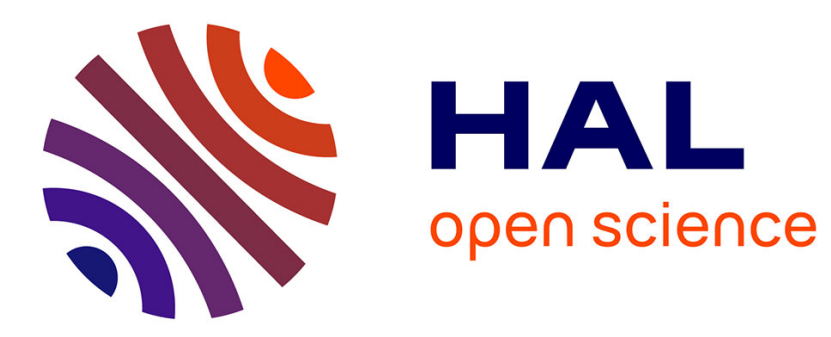

\title{
Comparative sensitivity analysis of four distributed erosion models
}

Bruno Cheviron, Yves Le Bissonnais, Jean-François Desprats, Alain Couturier, Silvio José Gumière, Olivier Cerdan, Frédéric Darboux, Damien Raclot

\section{- To cite this version:}

Bruno Cheviron, Yves Le Bissonnais, Jean-François Desprats, Alain Couturier, Silvio José Gumière, et al.. Comparative sensitivity analysis of four distributed erosion models. Water Resources Research, 2011, 47, pp.W01510. 10.1029/2010WR009158 . hal-00560466

\section{HAL Id: hal-00560466 https: / hal-brgm.archives-ouvertes.fr/hal-00560466}

Submitted on 29 May 2020

HAL is a multi-disciplinary open access archive for the deposit and dissemination of scientific research documents, whether they are published or not. The documents may come from teaching and research institutions in France or abroad, or from public or private research centers.
L'archive ouverte pluridisciplinaire HAL, est destinée au dépôt et à la diffusion de documents scientifiques de niveau recherche, publiés ou non, émanant des établissements d'enseignement et de recherche français ou étrangers, des laboratoires publics ou privés.

\section{다)(1) $(5$}

Distributed under a Creative Commons Attribution - NonCommercial| 4.0 International 


\title{
Comparative sensitivity analysis of four distributed erosion models
}

\author{
B. Cheviron, ${ }^{1,2}$ Y. Le Bissonnais, ${ }^{1}$ J. F. Desprats, ${ }^{3}$ A. Couturier, ${ }^{4}$ S. J. Gumiere, ${ }^{1}$ O. Cerdan, ${ }^{2}$ \\ F. Darboux, ${ }^{4}$ and D. Raclot ${ }^{5}$
}

Received 29 January 2010; revised 12 October 2010; accepted 26 October 2010; published 27 January 2011.

[1] Using a previously defined framework, we performed a comparative sensitivity analysis of four very different distributed erosion models (MHYDAS, STREAM, PESERA, and MESALES). We investigated their sensitivities to input fluxes, hydrological submodels, and specific erosion parameters gathered into equivalent slope and equivalent erodibility for each model, thus allowing explicit comparisons between models. Tests involved multiple combinations of rain intensities and runoff conditions for selected screenings of the equivalent parameter space, resorting to one-at-a-time displacements and Latin hypercube samples. Sensitivity to spatial distributions of erosion parameters was calculated as a normalized index of numerical spread of soil loss results, obtained at the outlet of a ninecell virtual catchment endowed with a fixed flow pattern. Spatially homogeneous or distributed parameterizations yielded responses of comparable magnitudes. Equivalent erodibility was often the key parameter, while sensitivity trends depended on input fluxes and the propensity of soils for runoff, affecting continuous and discrete models in clearly dissimilar ways.

Citation: Cheviron, B. Y. Le Bissonnais, J. F. Desprats, A. Couturier, S. J. Gumiere, O. Cerdan, F. Darboux, and D. Raclot (2011), Comparative sensitivity analysis of four distributed erosion models, Water Resour. Res., 47, W01510, doi:10.1029/2010WR009158.

\section{Introduction}

[2] Scenarios of climate change applied to the Mediterranean ring indicate high and increasing erosion risk: sparse vegetation, low structural stability, nonnegligible slopes, and intense rainstorms render soils especially prone to degradation and loss of fertility in northern Africa and southern Europe. Do model parameterizations correctly integrate these crucial elements, and what are the relative influences of the dedicated parameters on predicted erosion rates? Both problems may be tackled at once under the heading of sensitivity analysis, debating here theoretical aspects of erosion modeling through a cross-scale comparison of four very different models, following the framework presented by Cheviron et al. [2010]. The models are used for soil loss predictions at individually different spatial and temporal scales, ranging across experimental sites, instrumented catchments, and entire regions.

[3] Very different concepts underlie models intended for different scales, but the general trend is a progressively more refined description when smaller spatial extensions and time intervals are considered. In Distributed Hydrological Modeling for Agrosystems (MHYDAS)-Erosion [Gumiere et al., 2010] these dimensions are reduced to the

\footnotetext{
${ }^{1}$ UMR LISAH, INRA-IRD-SupAgro, Montpellier, France

${ }^{2}$ BRGM-RNSC, Orléans, France

${ }^{3}$ BRGM-RNSC, Montpellier, France

${ }^{4}$ UR 272, Science du Sol, Centre de recherche d'Orléans, INRA, Orléans, France

${ }^{5}$ UMR LISAH, INRA-IRD-SupAgro, Tunis, Tunisia
}

Copyright 2011 by the American Geophysical Union. 0043-1397/11/2010WR009158 elementary size of the event: a single and spatially homogeneous rain falls on a small agricultural catchment. Physical processes in detachment, transport, and deposition of particles are described with the level of detail allowed by the preexisting MHYDAS hydrological model [Moussa et al., 2002], where flow routing is computed from solutions of the one-dimensional Saint-Venant equations [Moussa and Bocquillon, 1996a, 1996b]. At intermediate spatial scales and for a succession of rain events, the semiempirical Sealing and Transfer by Runoff and Erosion Related to Agricultural Management (STREAM) model [Cerdan et al., 2002a, 2002b] calculates water and sediment fluxes from surface sealing, land cover, digital elevation models, and flowcharts in agricultural catchments. It was built to work with a limited number of easily measured field parameters and designed for land management purposes. At larger scales, the Pan-European Soil Erosion Risk Assessment (PESERA) model [Gobin et al., 2004; Kirkby et al., 2008] relies on monthly statistical climatic data and integrates transient land cover scenarios associated with cropping seasons. It belongs to the "simplified physics-based" category of erosion models in the classification by Merritt et al. [2003]. For equally large scales, the expert model Regional Modeling of Soil Erosion Risk (MESALES) [Le Bissonnais et al., 2002] uses a decision tree to combine values of crusting, slope, erodibility, land use, and rain inputs into discrete classes of erosion risks. A conversion is then possible into continuous soil losses values in tons per hectare and per year.

[4] Recent literature reviews [Knapen et al., 2007; Gumiere et al., 2009] report a possible higher sensitivity of erosion results to hydrological parameters than to specific erosion parameters, although warning that studies are often conducted under high rain intensities. Only a few hydrological 
conditions have been tested in studies of WEPP [Nearing et al., 1990], LISEM [de Roo et al., 1996; Jetten et al., 1998], EUROSEM [Veihe and Quinton, 2000], or PSEM2D [Nord and Esteves, 2005] in which these models all identified a major influence of hydrological conditions on erosion results. One may also remark that no formal attempt has yet been made to discriminate between the effects of hydrological conditions and specific erosion parameters on soil loss results while addressing the inaccuracy of in situ modeling [Jetten et al., 1999, 2003; Boardman, 2006], criticizing the likelihood of model predictions [Brazier et al., 2000], or proposing solutions [Jetten et al., 2005] to some of their major flaws.

[5] We present here a comparative sensitivity analysis of four very different erosion models by means of the $(P, R$, $p$ ) procedure exposed by Cheviron et al. [2010]. The procedure starts from an intelligent sorting of the innate parameters of each model into independent categories accounting for precipitation $(P)$, runoff conditions $(R)$, and erosion parameters $(p)$, comprising "equivalent slope" $\left(p_{s}\right)$ and "equivalent erodibility" $\left(p_{e}\right)$. The resulting reduced parameterization $\left(P, R, p_{s}, p_{e}\right)$ is common to all models being studied, for all their structural differences, which is a cornerstone of the present study and a novel idea with respect to current practices in model analysis. The $(P, R, p)$ benchmark is, indeed, adaptable to the widest variety of models. It was intended for the typical situation where knowledge of a given model is possessed by its users and decision makers only need overviews of the specificities of several candidate models.

[6] The analysis procedure is discriminating enough to separate the sensitivity to hydrological factors from that to erosion parameters: the relative influences of variations in input fluxes, runoff conditions, topography (slope), and soil properties (erodibility) may be estimated from deterministic and explicit calculations. Sensitivity trends arise from a series of scenarios involving selected variations in one or more of the parameters as well as in spatial distributions of the erosion parameters, which confers flexibility on the procedure and opens the way for ad hoc test designs. A case of scientific interest is, for example, to identify the hydrological conditions under which models are more sensitive to spatial distributions of their erosion parameters. Policy planners, however, may be more concerned about the drift in model predictions, with a progressive drift from best-case to worst-case scenarios, including strong rain and runoff, steep slopes, and high erodibility. Both questions are addressed in the present study, as illustrations of the more diverse results obtainable from this novel model analysis procedure.

\section{Materials and Methods}

\subsection{Models}

\subsubsection{MHYDAS}

[7] MHYDAS is a runoff-rainfall model developed to study the effects of agricultural management on the hydrological behavior of a farmed catchment during rain events [Moussa et al., 2002]. It relies on the one-dimensional description of flow routing in connected reach segments by means of the diffusive wave approximation of the SaintVenant equations, as solved by Moussa and Bocquillon [1996a, 1996b]. The MHYDAS-Erosion module was added recently to the OpenFluid development platform (Laboratoire d'études des Interactions Sol-Agrosystème-Hydrosytème (LISAH) Montpellier, France, 2010, available at http:// www.umr-lisah.fr/openfluid). MHYDAS-Erosion is a smallscale physics-based model with dedicated parameter sets for concentrated and diffuse erosion processes, with the former located in rills and the latter on interrills. This event-based model was intended for small Mediterranean catchments, as indicated by its typology and parameterization, where the number of rills and plot length (or streamwise distance) are key parameters. Sensitivity tests on MHYDAS were automated as indicated by Cheviron et al. [2010] thanks to a resolution scheme centered on the SENSAN software [Doherty, 2004].

\subsubsection{STREAM}

[8] STREAM was developed to account for the respective effects of slope and tillage directions on runoff [Souchere et al., 1998]. It grew into an event-based spatially distributed erosion model [Cerdan et al., 2002a, 2002b] with empirical inputs in the determination of its few innate parameters. It was conceived for agricultural management purposes, and its parameterization is based directly on field observations. Whereas MHYDAS-Erosion updates erosion calculations at each time step, STREAM yields cumulative results for concentrated and diffuse erosion over the entire duration of an event. The model has been recently described and successfully tested by Evrard et al. [2009] in three completely different contexts (northern France, Belgium, and southern France). Automation of tests performed on STREAM was made in an ad hoc procedure: models relying on geographical information systems with input and output files as worksheets would not fit in a resolution scheme commanded by SENSAN, which needs ASCII files to interact with models.

\subsubsection{PESERA}

[9] PESERA is a coarse-scale model [Gobin et al., 2004; Kirkby et al., 2008], intended for erosion risk assessment across Europe, relying on a refined meteorological submodel and on simplified physics-based equations for erosion. It was designed to estimate long-term average erosion rates in replacement of the universal soil loss equation, which is less suitable for European than for North American conditions and is not compatible with higher-resolution data. An evaluation of PESERA by Licciardello et al. [2009] in contrasting contexts revealed that variability between the investigated land uses and climate conditions was well captured, whereas absolute erosion rates were strongly underestimated. Soil erodibility was identified as a key parameter, confirmed by preliminary sensitivity tests conducted on each parameter of each model for the present study. Because the heart of PESERA is a series of three small executable files, the model could be run without difficulty within the intended resolution scheme.

\subsubsection{MESALES}

[10] MESALES [Le Bissonnais et al., 2002] was developed to assess soil erosion risk at the national and European scale. It is one of the thematic applications based on the Soil Geographical Database of Europe. MESALES uses expert-defined rules to combine factors influencing erosion, with strong influences of land cover and crust formation onto results expressed in five classes of erosion risks. Relying on a geographical information system, MESALES could not be automated and was run manually. 


\subsection{Sensitivity Analysis Procedure}

\subsubsection{Mathematics and Strategy}

[11] The present study is an application of the deterministic framework discussed by Cheviron et al. [2010] that relies on a series of selected scenarios in model exploration. These scenarios apply to models whose parameterizations have previously been reduced to a common description involving precipitation $P$ as input fluxes, runoff conditions $R$ as the propensity of soil for surface flows, equivalent slope $p_{s}$ accounting for all topographical entries, and equivalent erodibility $p_{e}$ indicating how soils are prone to erosion. The parameter space therefore has four dimensions: a point in parameter space is localized by its four coordinates $\left(P, R, p_{s}, p_{e}\right)$. Associated model responses $M\left(P, R, p_{s}, p_{e}\right)$ are "multilocal" quantities, i.e., quantities defined at multiple points corresponding to the tested combinations of $(P$, $R, p_{s}, p_{e}$ ) parameter values.

[12] Scenarios in model exploration are simply userdefined screenings of the parameter space, along trajectories and according to strategies constrained by the objectives attributed to the $(P, R, p)$ procedure. The first and global objective is a comparative overview of responses and sensitivity of the models over their entire parametric ranges. The second objective is to identify how sensitivity to equivalent slope and erodibility $\left(p_{s}, p_{e}\right)$ evolves under increasing $(P, R)$ hydrological conditions.

[13] For simplicity, let $X$ be a point in parameter space and $M(X)$ be the model response. Any screening is a succession of $\delta X$ increments along a selected trajectory involving variations in one or more of the parameters. Sensitivity is expressed as the associated $G_{\delta X}(X)=\delta M$ variation. It is termed "sensitivity at $X$ in the direction of $\delta X$ " and has the useful advantage of being a scalar value obtained from a vectorial displacement in parameter space. The underlying concept and calculation device is that of the Gâteaux directional derivatives [Gâteaux, 1913], which pertain to analysis of nonlinear discrete systems [Cacuci, 1981, 2003] with variational methods [Castaings, 2007; Castaings et al., 2007].

[14] This central mathematical argument makes the $(P, R$, $p$ ) procedure a simplified variational method in a formulation adapted to erosion models, considering a specific reduced parameterization and defining model response as the simplest possible output, i.e., cumulative (time-independent) soil loss. This strategy was chosen to erase structural differences between models and to place them on the same starting line before analysis, but the $(P, R, p)$ procedure could easily be modified to analyze multiple time-dependent outputs or to explicitly target the control exerted by boundary and initial conditions over the results, in a strategy close to data assimilation purposes. It could also handle distinct parameters for concentrated and diffuse erosion processes, if all models being tested had a sufficient level of detail.

\subsubsection{Virtual Catchment}

[15] In the $(P, R, p)$ procedure, the virtual catchment is the topographical entity on which soil loss and sensitivity calculations are performed. Its features are shown in Figure 1. Its topology is fixed. Flow paths remain unaffected by the driving rain conditions and are the only connectivity lines between cells in the catchment, with respect to hydrological and sedimentological processes. If not linked by a flow line,

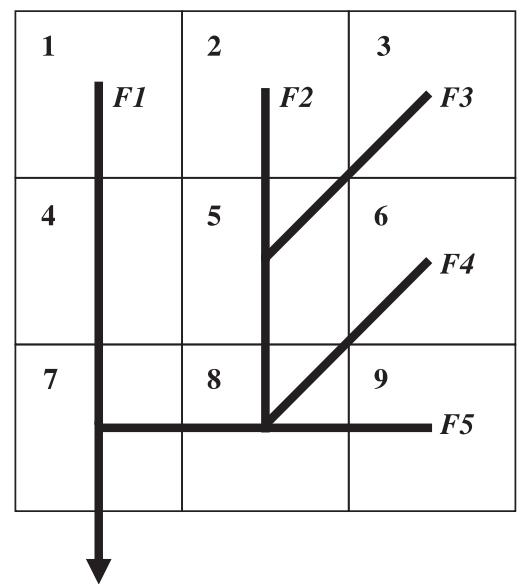

Figure 1. Layout and connectivity in the virtual catchment between surface units numbered 1 to 9 . The one-way downstream hydrological and sedimentological connectivity is indicated by flow lines numbered F1 to F5.

two adjacent cells have no interactions. For simplicity, all cells are arbitrarily represented by squares, but their length and width may vary if distance to the drainage line or streamwise distance has to be tested as a requirement of a given model. Conversely, the surface area of the elements must be kept constant and in accordance with the nominal spatial scale of models. The advantages and drawbacks of this virtual catchment have been discussed by Cheviron et al. [2010], with the concluding argument that enough diversity was present in this rather simple design to detect the major representative differences between models, at least those targeted by the intelligent (nonexhaustive) deterministic procedure.

\subsubsection{Spatialization of the Parameters}

[16] Only spatially homogeneous values of the hydrological factors accounting for precipitation $P$ and runoff conditions $R$ were considered here, to facilitate interpretation. Focusing on the role played by erosion parameters, both spatially homogeneous and spatially distributed configurations of the $p$ parameters were tested. Preliminary attempts with spatial distributions in all categories at once were discarded as they created too much equifinality in cumulative soil loss results. They are, nevertheless, useful when intending a temporal or cell-by-cell analysis, providing more diversity in the situations with far less redundancy.

[17] In spatially homogeneous $A$ configurations, a tested parameter has the same value in all cells, but a progressive gradation of values between simulations is considered. If, for example, three values $(p 1, p 2, p 3)$ are involved, they are previously sorted with regard to soil loss results, so that $p 1$ has the lowest contribution (or efficiency), $p 2$ the median one, and $p 3$ the highest one. When designing spatially distributed $B$ configurations, a limited number of contrasted configurations was chosen, in terms of spatial distributions and parameter values involved, as can be seen in Figure 2. $B$ configurations consist of patches of cells of low, median, and high efficiency superimposed on the flowchart. Model responses read $M\left(P, R, B_{s}, p_{e}\right), M\left(P, R, p_{s}, B_{e}\right)$, or $M(P, R$, $B_{s}, B_{e}$ ) for spatially distributed slopes, erodibilities, or both, respectively. 

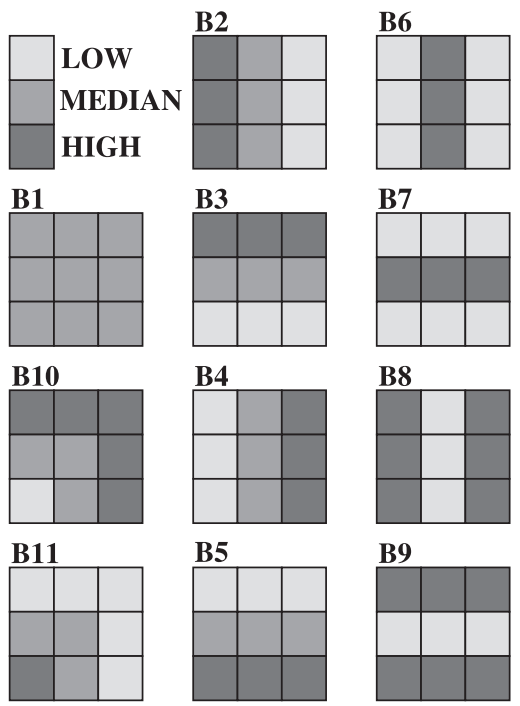

B3

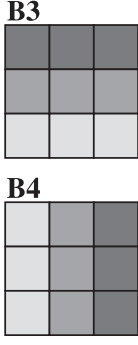

B5

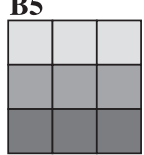

B7

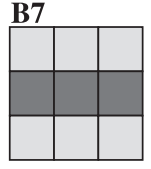

B8

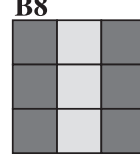

B9

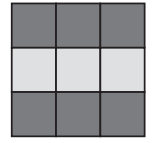

Figure 2. Spatially distributed $B$ configurations. Light, medium, and dark gray cells receive values of erosion parameters associated with low, median, and high efficiency with respect to soil loss, respectively.

\subsubsection{Equivalent Parameters}

[18] Besides common patterns for topography, topology, and spatial distributions of the $(P, R, p)$ entries, a reliable comparison between models requires definition and coding of equivalent $(P, R, p)$ entries. As units for $(P, R, p)$ values differ between models, no straightforward numerical com- parison could be planned. For each model, the coverage of the entire nominal range of each $P, R$, and $p$ axis involved unit increments: values of dissimilar nature were converted into comparable nondimensional entries represented by integers (Figure 3).

[19] For both the $A$ and $B$ configurations, tests on MHYDAS involved $5 P, 5 R, 11 p_{s}$, and $11 p_{e}$ values. Precipitation intensities were $P 1=20, P 2=35, P 3=50, P 4=65$, and $P 5=80 \mathrm{~mm} \mathrm{~h}^{-1}$. Runoff conditions were formed by $\left(K_{s}, \theta_{i}\right)$ combinations of saturated hydraulic conductivity $K_{s}$ and initial surface water content $\theta_{i}$ values, from $R 1$, given as $\left(K_{s}=37 \mathrm{~mm} \mathrm{~h}^{-1}, \theta_{i}=0.02\right)$, to $R 5$, given as $\left(K_{s}=0.1 \mathrm{~mm} \mathrm{~h}^{-1}, \theta_{i}=0.40\right), \quad$ in increasing efficiency order. Slope values were taken between $1 \%$ for the least and $30 \%$ for the most productive condition. The efficiency of the group of parameters constituting the equivalent erodibility was influenced by parameters accounting for the number of rills, interrill erodibility, cohesion in rills, and rill rugosity for low to median $(P, R)$ conditions, then controlled overall (with exponential effects) by parameters accounting for the number of rills and plot length (streamwise distance) for high $(P, R)$ conditions.

[20] Tests on STREAM involved five $P$ and three $R$ values. Precipitation intensities were chosen to match those tested for MHYDAS. Increasing $R$ conditions were obtained from pairs of increasing antecedent rain values and classes of sensitivity to runoff. Equivalent slope values from $1 \%$ to $30 \%$ were simulated in the digital elevation model required by STREAM, but only $p_{s}$ values corresponding to $1 \%, 3 \%$, $10 \%$, and $30 \%$ were tested in $A$ configurations. Five out of the possible 11 values of $p_{e}$ were tested in $A$ configurations,

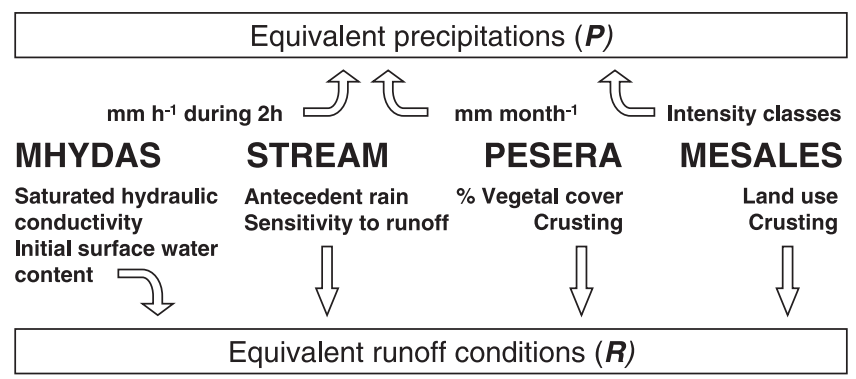

(a)

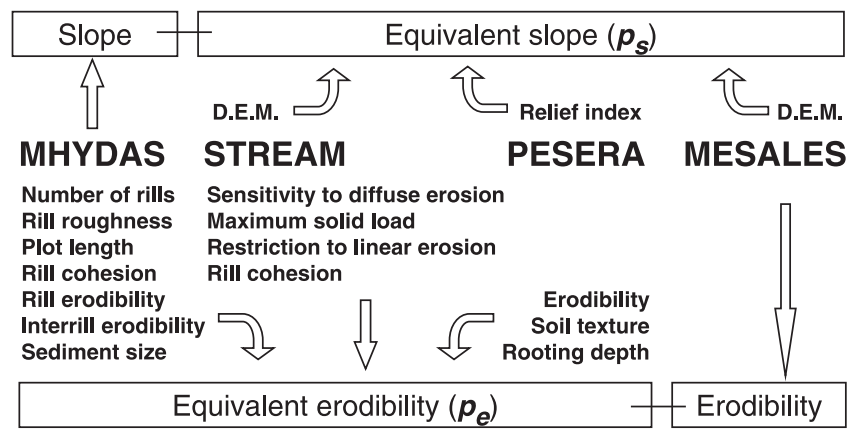

(b)

Figure 3. Innate entries of each model chosen for definition of (a) equivalent control hydrological conditions and (b) equivalent "descriptive" parameters of slope and erodibility. Slope appears as such in the innate parameterization of MHYDAS, as does erodibility in MESALES. 
with none of the constitutive elements of equivalent erodibility showing a dominating influence.

[21] Tests on PESERA involved six $P$ values, but only five appear in the presentation of the results, corresponding to precipitation intensities of $35,55,75,95$, and $115 \mathrm{~mm} \mathrm{month}^{-1}$. In its meteorological parameterization, PESERA also includes a number of rainy days per month and a coefficient of rainfall variation that accounts for fluctuation in intensity of the precipitation, but the influences of these parameters were found to be of secondary order: they were kept at their recommended default values. Annual sine temperature variations were treated the same way. Increasing runoff conditions were thought of as combinations of decreasing percentage of vegetal cover with increasing soil crusting values, yielding five $R$ values. The least efficient condition has $100 \%$ surface cover and $1 \mathrm{~mm}$ crusting; the most efficient has bare soil with $5 \mathrm{~mm}$ crusting. Eleven equivalent slopes from $1 \%$ to $30 \%$ were produced, resorting to the same strategy as for STREAM, feeding PESERA with the adequate relief index required. Equivalent erodibility was strongly conditioned by the innate erodibility parameter: parameters accounting for soil texture and rooting depth played secondary, though nonnegligible, roles, with a noticeable effect confined in low $(P, R)$ conditions.

[22] MESALES was tested under five classes of increasing precipitation intensities. The difficulty was to find three unambiguously increasing runoff conditions. The only way to perform a $(P, R, p)$ analysis of MESALES and to ensure comparison with other models was to define runoff conditions as the combination of a given land use and a given crusting value, but the former function raised serious issues. We had to choose very contrasted land uses to create a progression between $R$ values, which required testing almost all nine land use classes listed in MESALES before choosing three of them. $R 1$ was finally defined as forest with class 1 crusting, $R 2$ as vineyards with class 3 crusting, and $R 3$ as arable land with class 5 crusting. The same strategy as for STREAM and PESERA was used to simulate the intended slopes from digital elevation model requirements. Erodibility and equivalent erodibility are strictly identical in MESALES.

\subsubsection{Screenings}

[23] Figure 4a shows explorations of the $\left(p_{s}, p_{e}\right)$ plane when dealing with $A$ configurations. Four trajectories are followed, involving one-at-a-time (OAT) or Latin hypercube (LH) displacements, indicated by small solid and large open circles, respectively. Along the vertical sequence of solid circles, increasingly efficient configurations of the equivalent erodibility are tested, whereas equivalent slope is held at its median value in all cells, which is denoted $\operatorname{OAT}\left(p_{e}\right)$. Roles are exchanged when considering the horizontal sequence of solid circles, indicated as $\mathbf{O A T}\left(p_{s}\right)$. Along the first diagonal, simultaneously increasing values of $p_{s}$ and $p_{e}$ are tested, denoted $\mathbf{L H}\left(p_{s}, p_{e}\right)$. Along the second diagonal, $p_{s}$ is increased while $p_{e}$ is decreased. Such a representation holds for given $(P, R)$ conditions.

[24] The vertical sequence of solid circles in Figure $4 \mathrm{~b}$ indicates tests performed with spatially distributed $B_{e}$ configurations while $p_{s}$ is held at its median value in all cells. As soil loss results are sorted by increasingly efficient $B_{e}$ configurations, the test is denoted $\mathbf{O A T}\left(B_{e}\right)$. The same applies for the horizontal sequence $\mathbf{O A T}\left(B_{s}\right)$ of solid (a)
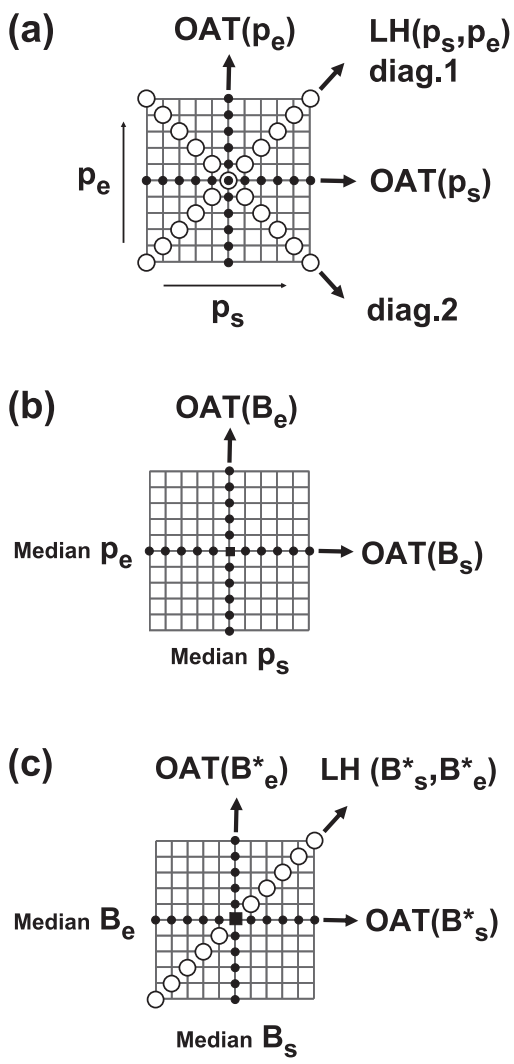

Figure 4. Screening stages and strategies, involving tests on the equivalent slope $p_{s}$ and equivalent erodibility $p_{e}$ in (a) spatially homogeneous or $(b, c)$ distributed configurations, where equivalent parameters are denoted $B_{s}$ and $B_{e}$, respectively. One-at-a-time (OAT) and Latin hypercube (LH) explorations are assembled into sensitivity maps.

circles when exchanging roles. These sequences were placed perpendicular to one other to facilitate representation of the results, even if the center of the diagram a priori bears two different soil loss values: $\left(p_{s}=6, B_{e}=6\right)$ and $\left(B_{s}=6, p_{e}=6\right)$. This artifact is evaluated later to compare the effects of distributions in equivalent slope and equivalent erodibility.

[25] Figure $4 c$ goes one step further in analyzing the influence of spatial distributions of the equivalent parameters. The vertical sequence of solid circles corresponds to the test of spatial distributions $B_{e}$ while $B_{s}$ is held at its median-efficiency distributed configuration. Configurations are again sorted by increasing efficiency, along the $\mathbf{O A T}\left(B_{e}^{*}\right)$ direction. The same applies for the horizontal sequence OAT $\left(B_{s}^{*}\right)$ of solid circles when exchanging roles. The $\mathbf{O A T}\left(B_{s}^{*}, B_{e}^{*}\right)$ test involves increasingly efficient spatial distributions $B_{s}$ and $B_{e}$. In cases where soil loss results were not monotonically increasing along the first diagonal, they were resorted to fulfill this requirement. The "improper" graphical representation proposed in Figure $4 \mathrm{~b}$ was also used in Figure $4 \mathrm{c}$ to compare the magnitude of soil loss values obtained in the three different directions of OAT and LH tests.

\subsubsection{Sensitivity Indices}

[26] If soil loss values $M\left(P, R, p_{s}, p_{e}\right)=M(X)$ are placed on the OAT and LH nodes of the grid, as indicated in 
Figure $4 \mathrm{a}$, then selected displacements $\operatorname{OAT}\left(p_{s}\right), \operatorname{OAT}\left(p_{e}\right)$, or $\mathbf{L H}\left(p_{s}, p_{e}\right)$ result in $\delta M$ variations unambiguously associated with sensitivities $G_{\delta p_{s}}(X), G_{\delta p_{e}}(X)$, and $G_{\delta p_{s}+\delta p_{e}}(X)$, respectively. In simplified notation, these sensitivities are all of the $G_{p}$ type. Accordingly, $G_{p}$ and $G_{R}$ are sensitivities to variations in $P$ and $R$ conditions.

[27] Besides these multilocal values, a complementary sensitivity information is the dispersion $\mathbf{S A}$ of the soil loss results associated with screenings described in Figure 4a, depending on the $(P, R)$ conditions. When performing the $\operatorname{OAT}\left(p_{s}\right)$ test, this normalized dispersion is

$$
\mathbf{S A}(\mathbf{s})=\frac{M\left(P, R, p_{s}^{+}, p_{e}^{m}\right)-M\left(P, R, p_{s}^{-}, p_{e}^{m}\right)}{M\left(P, R, p_{s}^{m}, p_{e}^{m}\right)},
$$

where superscripts plus, $m$, and minus indicate values associated with maximum, median, and minimum efficiency with respect to soil loss. $\mathbf{S A}(\mathbf{e})$ is defined in a similar way to $\operatorname{OAT}\left(p_{e}\right)$. The dispersion associated with $\mathbf{L H}\left(p_{s}, p_{e}\right)$ in Figure $4(\mathrm{a})$ is

$$
\mathbf{S A}(\mathbf{s}, \mathbf{e})=\frac{M\left(P, R, p_{s}^{+}, p_{e}^{+}\right)-M\left(P, R, p_{s}^{-}, p_{e}^{-}\right)}{M\left(P, R, p_{s}^{m}, p_{e}^{m}\right)} .
$$

[28] Dispersion values may also be calculated from displacements shown in Figure 4(b), measuring the sensitivity to individual spatial distributions $B_{s}$ or $B_{e}$. In the former case, $\mathbf{S B}(\mathbf{s})$ is obtained from $\mathbf{O A T}\left(B_{S}\right)$ and is defined as the normalized spread:

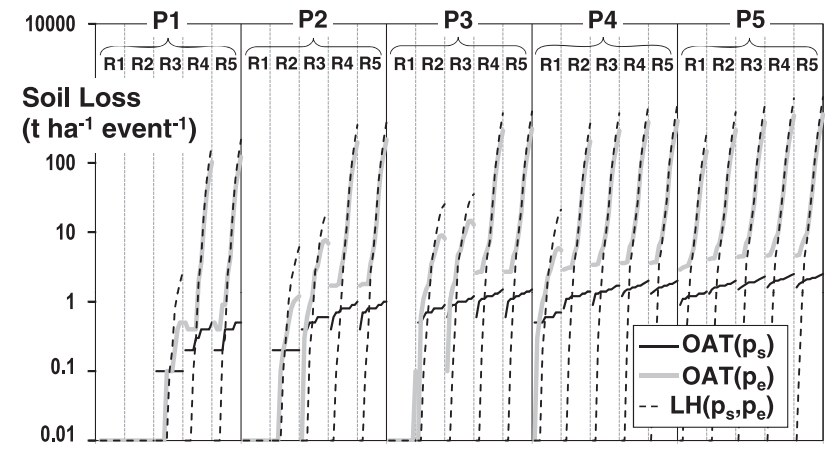

(a) MHYDAS - model results in homogeneous configurations

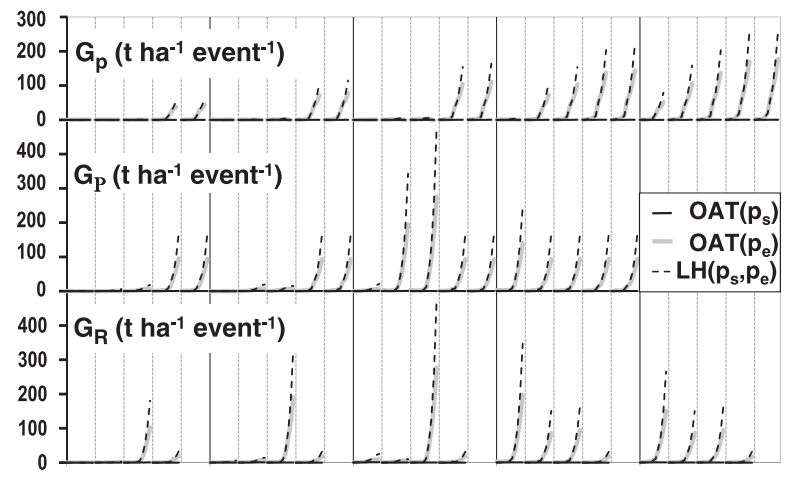

(c) MHYDAS - sensitivities in homogeneous configurations

$$
\mathbf{S B}(\mathbf{s})=\frac{M\left(P, R, B_{s}^{+}, p_{e}^{m}\right)-M\left(P, R, B_{s}^{-}, p_{e}^{m}\right)}{M\left(P, R, p_{s}^{m}, p_{e}^{m}\right)} .
$$

[29] The last sensitivity measure is obtained from displacements in Figure $4 \mathrm{c}$ and indicates the effects of combined spatial distributions $B_{s}$ and $B_{e}$. For example, OAT $\left(B_{s}^{*}\right)$ results in the $\mathbf{S B}^{*}(\mathbf{s})$ dispersion:

$$
\mathbf{S B}^{*}(\mathbf{s})=\frac{M\left(P, R, B_{s}^{+}, B_{e}^{m}\right)-M\left(P, R, B_{s}^{-}, B_{e}^{m}\right)}{M\left(P, R, p_{s}^{m}, p_{e}^{m}\right)} .
$$

[30] Together with selected representations of model results $M$, three multilocal quantities $\left(G_{p}, G_{P}\right.$, and $\left.G_{R}\right)$ and three measures of dispersion $\left(\mathbf{S A}, \mathbf{S B}\right.$, and $\left.\mathbf{S B}^{*}\right)$ are therefore used in this study to evaluate sensitivity trends obtained from screenings involving $p_{s}, p_{e}, B_{s}$, and $B_{e}$, performed under varied $(P, R)$ conditions.

\section{Results and Discussion}

\subsection{Spatially Homogeneous Configurations}

3.1.1. MHYDAS

[31] Throughout this study, the $M\left(P, R, p_{s}, p_{e}\right)$ formulation of model response involves five quantities. The problem has, therefore, five dimensions, but only a planar representation allows plotting sufficiently detailed and clear information, with the arguments of $M$ on the $X$ ordinate and $M$ values on the $Y$ ordinate. Figure 5a exemplifies this graphical

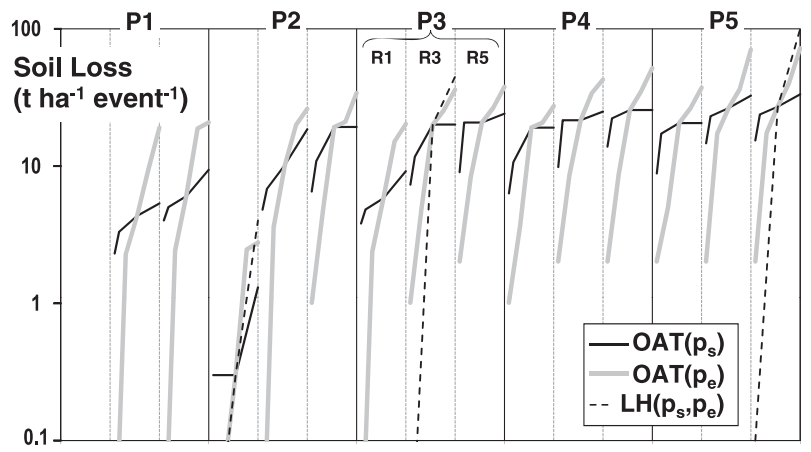

(b) STREAM - same key as (a)

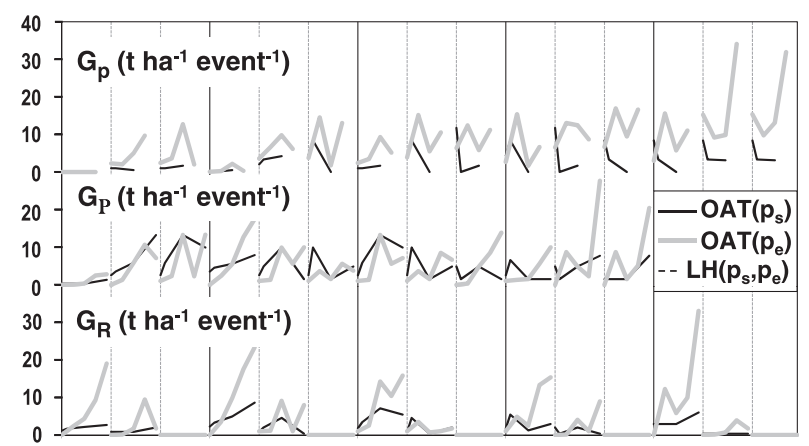

(d) STREAM - same key as (c)

Figure 5. Dashboards representing soil loss and sensitivity results for (a, c) MHYDAS and (b, d) STREAM under all combinations of precipitation $P$ and runoff conditions $R$ for OAT and LH screenings involving spatially homogeneous values of the equivalent slope $p_{s}$ and/or erodibility $p_{e}$. 
facility: $M$ values obtained from $\mathbf{O A T}\left(p_{s}\right), \mathbf{O A T}\left(p_{e}\right)$, and $\mathbf{L H}\left(p_{s}, p_{e}\right)$ in Figure 4 a are shown for all combined $(P, R)$ conditions. A dashboard is constituted by placing Figure $5 \mathrm{c}$ under Figure 5a, so that soil loss results and the associated sensitivities belong to the same column spanning both plots. In Figure $5 \mathrm{c}, G_{p}$ indicates the variation in soil loss caused by a unit increment in $p_{s}$ for the $\mathbf{O A T}\left(p_{s}\right)$ screening, in $p_{e}$ for the $\mathbf{O A T}\left(p_{e}\right)$ screening, or in $p_{s}$ and $p_{e}$ simultaneously for the $\mathbf{L H}\left(p_{s}, p_{e}\right)$ screening. $G_{P}$ and $G_{R}$ are the variations caused by unit increments in $P$ and $R$, respectively.

[32] Soil loss results in Figure 5a show a wide dispersion over several orders of magnitude, with much more sensitivity to $p_{e}$ than to $p_{s}$. LH tests indicate an even wider spread of values. Values are driven to near zero by the influence of low slopes, then stretched up to high values under exponential influences of factors taking part in the definition of equivalent erodibility, previously cited as the number of rills and streamwise distance. In Figure 5c, values of the derivatives are of almost the same order of magnitude as soil loss results, indicating a very dynamic response of the model. The global trend in $G_{p}$ curves indicates an increase in sensitivity for increasing $(P, R)$ conditions. The $G_{p}$ curves indicate a maximum sensitivity to $P$ for middle-range $(P, R)$ conditions, corresponding to the typical nominal range of the model. A plausible explanation is that such $(P, R)$ regimes are critical water excess conditions under which diffuse erosion dominates (high $G_{P}$ and $G_{R}$ values) and over which linear erosion is triggered, progressively taking over (lowering $G_{P}$ and $G_{R}$ values). For very high water excess conditions, diffuse erosion provides a negligible contribution so that the model output is not significantly sensitive to increases in $P$ or $R$.

\subsubsection{STREAM}

[33] Figure 5b shows that $\mathbf{L H}\left(p_{s}, p_{e}\right)$ screenings for STREAM were limited to $(P 2, R 1),(P 3, R 2)$, and $(P 5, R 3)$ conditions. Because of the presence of only three $R$ conditions, one easily observes the intersection between curves in the dotted columns, corresponding to the central point of the diagram in Figure 4a. In these small so-called "spider diagrams," soil loss values are far less dispersed than for MHYDAS, though exhibiting comparable orders of magnitude. STREAM has a less dynamic response but also exhibits a stronger sensitivity to $p_{e}$ than to $p_{s}$, with magnified but not so spectacular effects associated with $\mathbf{L H}\left(p_{s}, p_{e}\right)$ screenings. The order of magnitude of the derivatives in Figure $5 \mathrm{~d}$ is inferior to that of the soil loss results, with some specific exceptions: values of $G_{p}, G_{P}$, and $G_{R}$ associated with the OAT $\left(p_{e}\right)$ screening become high for high $(P, R)$ conditions, which possibly indicates the beginning of an exponential behavior and requires tests in a wider range of values. Other noticeable features are high values of $G_{P}$ and $G_{R}$ corresponding to the appearance of nonzero responses for low to medium $(P, R)$ conditions. In particular, the curves for $(P 2, R 1)$ in Figure $5 \mathrm{~b}$ probably signal the threshold between influences of diffuse and linear erosion, though less clearly than for MHYDAS.

\subsubsection{PESERA}

[34] Figures 6a and 6c show very smooth soil loss and sensitivity results over several orders of magnitude, with steeper response curves for LH screenings and OAT tests on equivalent erodibility than for OAT tests on equivalent slope. PESERA has slightly more sensitivity to $R$ than to $P$, but both have significant influences on the results, though variations in $p_{e}$ remain the dominant factor. Unlike in MHYDAS, no distinction is made between diffuse and linear erosion processes, which explains why no threshold appears on PESERA curves for increasing $(P, R)$ conditions. As for MHYDAS, values of the derivatives in Figure $6 \mathrm{c}$ are high compared to soil loss values. $G_{p}$ increases with increasing $P, R$, and $p$ values, accelerating into a seemingly exponential behavior for the highest $(P, R)$ conditions. A possible explanation may be found in the physics-based and continuous model rationale, not including any cutoff or stabilization procedure more likely to be integrated in discrete models. In contrast, curves for $G_{P}$ and $G_{R}$ quickly reach a stable and autoreproduced pattern for median then high $(P, R)$ conditions. Note that the sixth $P$ condition tested for PESERA $\left(P=135 \mathrm{~mm} \mathrm{~h}^{-1}\right)$ was used to trace the rightmost part of the $G_{P}$ curve, tracing sensitivity to a unit increment from the fifth to the sixth $P$ value.

\subsubsection{MESALES}

[35] To allow for comparisons with other models, the five classes or erosion risks predicted by MESALES have been converted into soil loss values of 0.5, 2, 6.5, 20, and $50 \mathrm{t} \mathrm{ha}^{-1} \mathrm{yr}^{-1}$, respectively. As for PESERA, soil loss results were obtained cell by cell, as the flow pattern imposed in Figure 1 was not compatible with the requirements of these models, which do not include connectivity between cells. For these models, soil loss values presented here are averages over the nine-cell catchment.

[36] Figure 6b indicates that only $\mathbf{L H}\left(p_{s}, p_{e}\right)$ screenings were performed under $P 2$ and $P 4$ conditions, keeping with the general trend of an expected increase of soil loss values with increasing $P$ conditions. In Figure 6d, model derivatives $G_{p}$ and $G_{R}$ have higher absolute values than $G_{P}$. They become very significant in high $(P, R)$ conditions, identifying the progressively more dynamic behavior of the model.

\subsubsection{Sensitivity Maps}

[37] Figure 7 presents "sensitivity maps" that focus on the relative importance of equivalent slope $\left(p_{s}\right)$ and equivalent erodibility $\left(p_{e}\right)$ for each model, under three increasing $(P, R)$ water excess conditions. This graphical facility relies on all screenings depicted in Figure 4a, including the second diagonal, but involves only selected $(P, R)$ combinations, which offers complementary information to that contained in the model dashboards.

[38] The orientation of isovalues indicates similar sensitivity trends for MHYDAS, STREAM, and PESERA. In the $\left(p_{s}, p_{e}\right)$ plane, a displacement along the $X$ ordinate induces less change in soil loss values than a displacement of the same magnitude along the $Y$ ordinate: variations in equivalent erodibility have more pronounced effects. The effects of combined variations are stronger, however, stretching values along the first diagonal, from the lower left to the upper right of each plot, on the line between best-case and worst-case scenarios. MHYDAS and PESERA exhibit very dynamic, if not exponential, behavior along such trajectories, especially in high water excess conditions. Figures $7 \mathrm{a}$ and $7 \mathrm{~b}$ for MHYDAS reveal slight anomalies for median to low slopes, high equivalent erodibilities, and limited water excess conditions. For MESALES, erodibility and equivalent slope show comparable importances, but Figure 71 is an exception: equivalent slope regains a first-order influence under high precipitation values. 


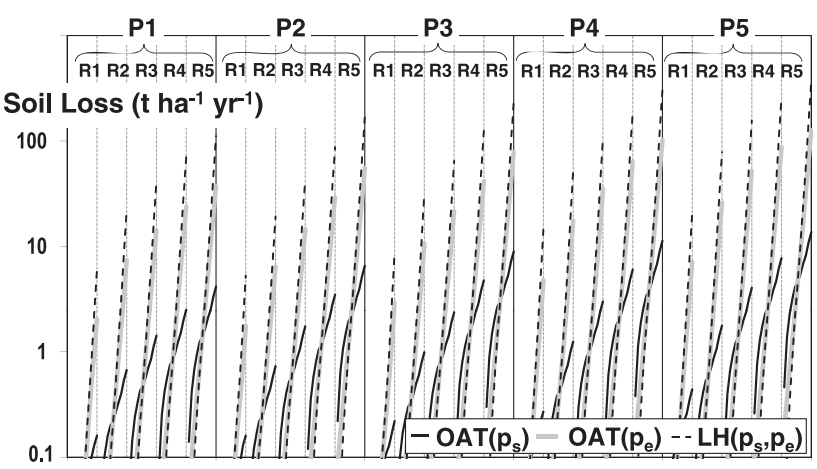

(a) PESERA - model results in homogeneous configurations

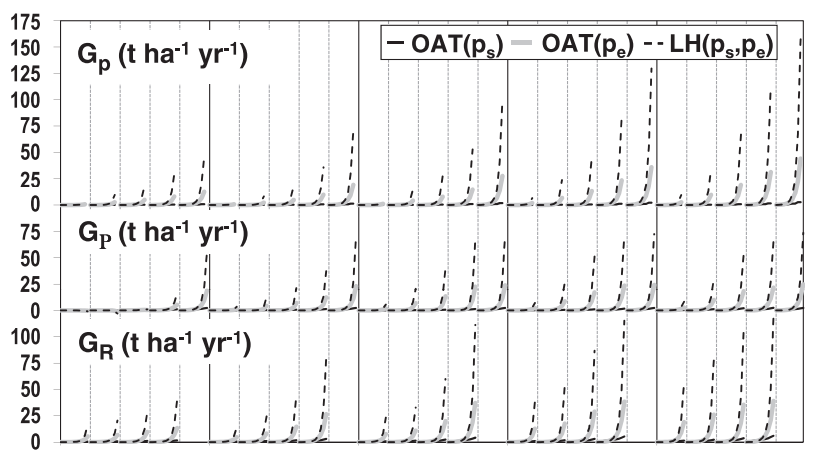

(c) PESERA - sensitivities in homogeneous configurations

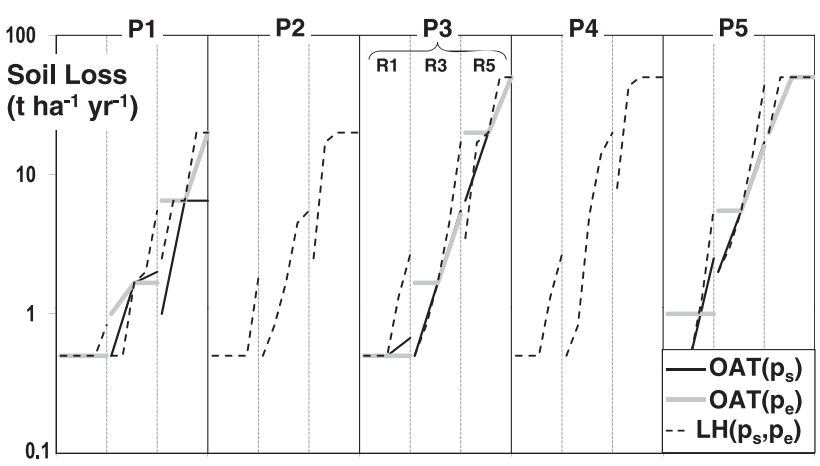

(b) MESALES - same key as (a)

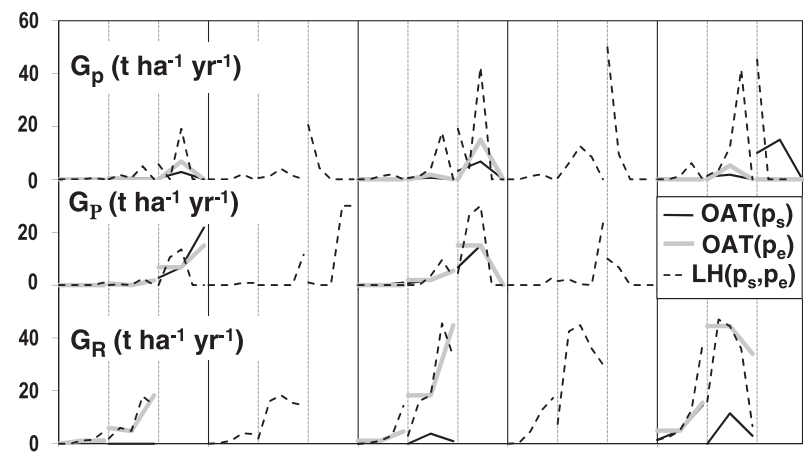

(d) MESALES - same key as (c)

Figure 6. Dashboards representing soil loss and sensitivity results for (a, c) PESERA and (b, d) MESALES under all combinations of precipitation $P$ and runoff conditions $R$ for OAT and LH screenings involving spatially homogeneous values of the equivalent slope $p_{s}$ and/or erodibility $p_{e}$.

\subsection{Spatially Distributed Configurations}

\subsubsection{MHYDAS}

[39] Comparing soil loss values obtained from screenings depicted in Figure 4b, Figure 8 a shows greater dispersion of the results associated with $\mathrm{OAT}\left(B_{e}\right)$. The OAT $\left(B_{s}\right)$ screening yields predicted values inferior by at least one order of magnitude. Although obvious, these discrepancies remain somewhat weaker than those in Figure 5a. The expected increase in soil loss results with increasing $R$ values is very limited when testing $B_{e}$ configurations and becomes even untrue when testing $B_{s}$. In MHYDAS, for fixed $P$ and median $p_{e}$ values, i.e., for a given amount of available water and for known soil characteristics, changes in $R$ and $B_{s}$ both affect flow routing algorithms, which leaves the possibility for variations in $B_{s}$ to overcompensate for the increase in spatially homogeneous $R$ conditions. This scenario is very plausible, as the most efficient $B_{S}$ configurations were found to vary with $R$. In contrast, the most productive patterns for $B_{e}$ are $B 2, B 10, B 8$, and $B 7$, for all $(P, R)$ conditions and for median $p_{s}$ values. Figure $8 \mathrm{c}$ plots normalized dispersion values $\mathbf{S B}(\mathbf{s})$ and $\mathbf{S B}(\mathbf{e})$ calculated from equation (3), as well as their variations $\mathbf{G}_{\mathbf{P}}(\mathbf{S B})$ and $\mathbf{G}_{\mathbf{R}}(\mathbf{S B})$ for unit increments in $P$ and $R$, respectively. Except for low water excess conditions, $\mathbf{S B}(\mathbf{s})$ remains close to unity, indicating no significant effect of the $B_{s}$ distributions, whereas $\mathbf{S B}(\mathbf{e})$ is about 100: calculated soil losses vary between 0 and 100 times the reference value when testing $B_{e}$. An asymptotic regime seems to be reached when advancing toward the right of Figure $8 \mathrm{c}$, as $\mathbf{S B}(\mathbf{e})$ stabilizes while its derivatives progressively tend to zero.

\subsubsection{STREAM}

[40] The very stable and bounded soil loss results for STREAM in Figure $8 \mathrm{~b}$ resemble these of Figure $5 \mathrm{~b}$, with even less dispersion and fewer discrepancies between curves. Depending on the $(P, R)$ conditions, the most productive configurations were $B 1$ or $B 2$ for $B_{S}$ and $B 9$ or $B 2$ for $B_{e}$. Soil loss values are comparable with those predicted by MHYDAS when considering the OAT $\left(B_{s}\right)$ screening, but they are about one order of magnitude lower than with $\operatorname{OAT}\left(B_{e}\right)$. Values of SB(e) for STREAM are negligible compared to those of MHYDAS, except for the low water excess conditions on the left of Figure 5d, corresponding to the appearance of nonzero predicted soil losses.

\subsubsection{PESERA}

[41] Figure 9a shows soil loss results obtained for PESERA from OAT $\left(B_{s}\right)$ and OAT $\left(B_{e}\right)$ screenings in Figure $4 \mathrm{~b}$. A striking feature of Figure $9 \mathrm{a}$ is the organization of model results into steps of values for any given $(P, R)$ combination. More detailed representations would, indeed, show six discrete levels of values inside each dotted column, as equal results are obtained from six subfamilies of $B$ configurations, namely, $B 11, B 1, B 6$ and $B 7, B 2-B 5$, $B 10$, and $B 8$ and $B 9$, in increasing efficiency order for $B_{e}$. This order is almost the same for $B_{e}$, except that $B 1$ comes before $B 11$. These discrete levels are a consequence of the fact that the imposed flowchart is not relevant and not taken 


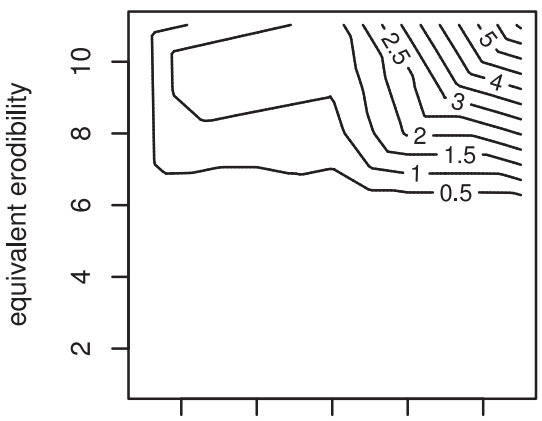

a) $2 \quad \begin{array}{lllll}4 & 6 & 8 & 10\end{array}$

equivalent slope

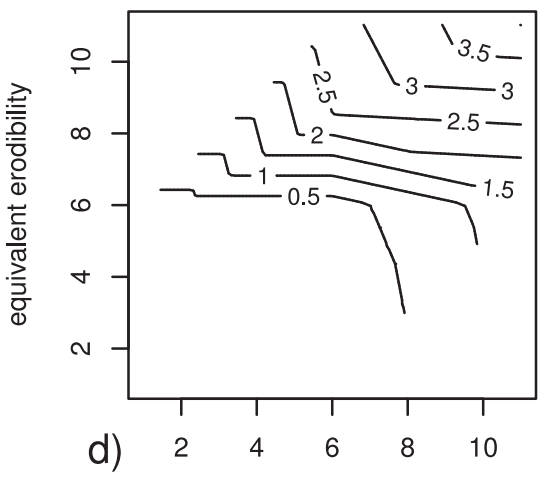

equivalent slope

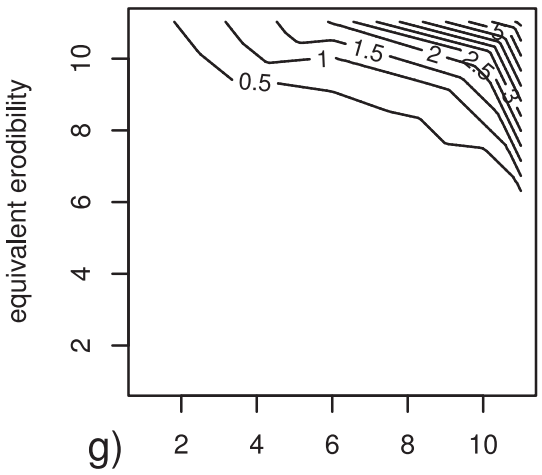

equivalent slope

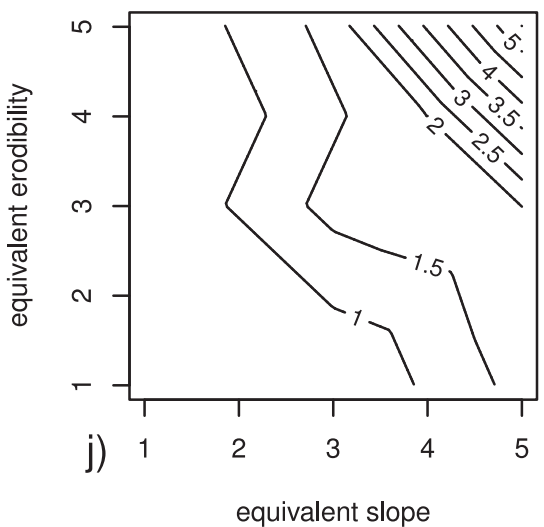

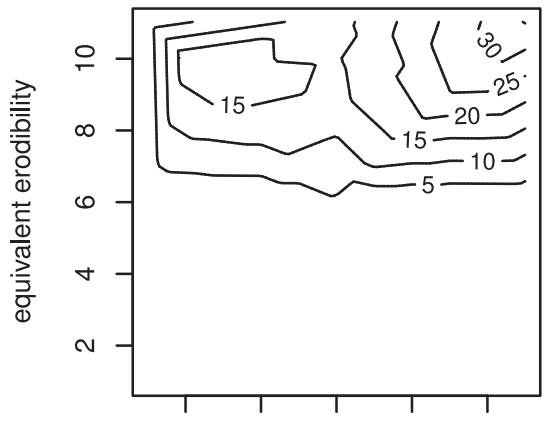

b) $2 \quad 4 \quad 6 \quad 8 \quad 10$

equivalent slope

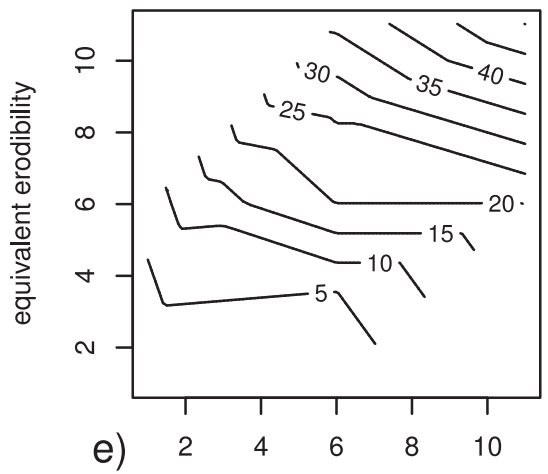

equivalent slope

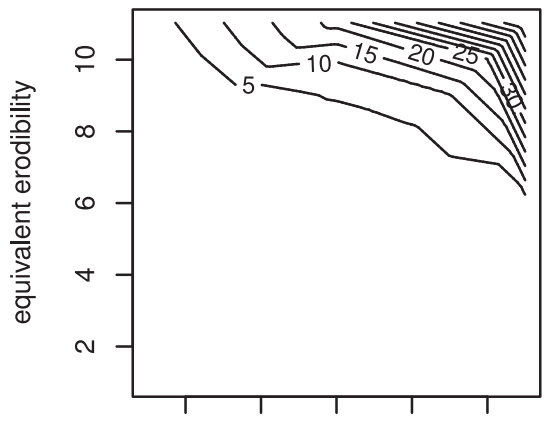

h) $2 \quad 4 \quad 6 \quad 8 \quad 10$

equivalent slope

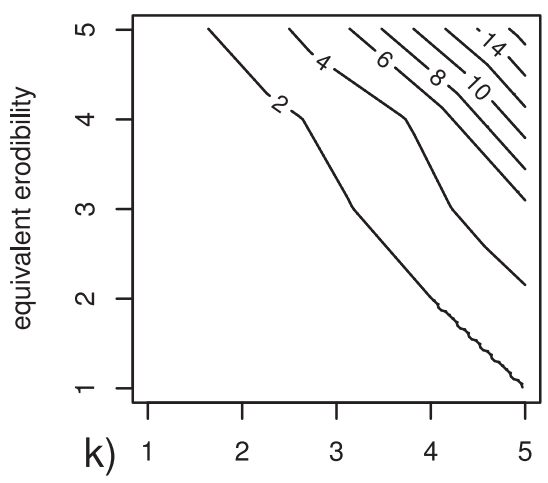

equivalent slope

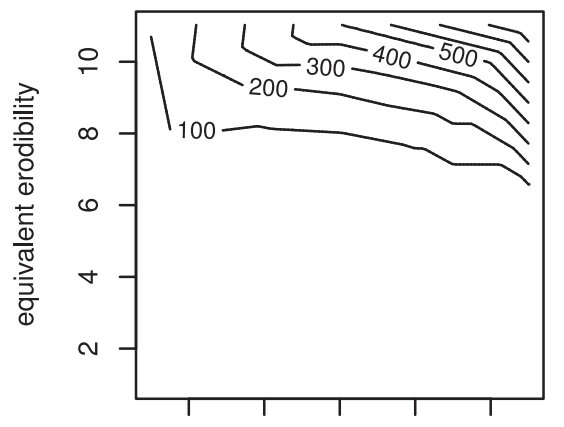

C) $2 \quad 4 \quad 6 \quad 8 \quad 10$

equivalent slope

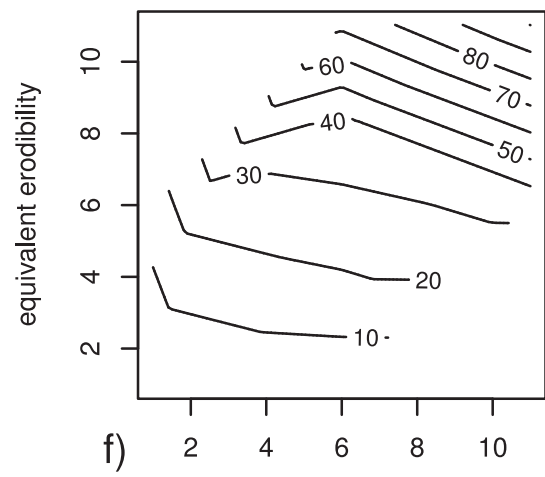

equivalent slope

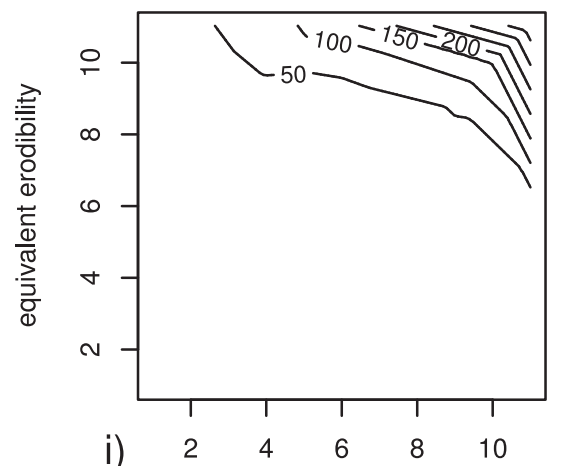

equivalent slope

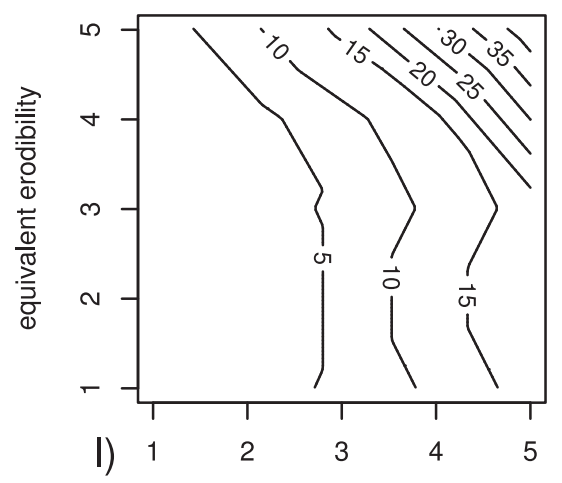

equivalent slope

Figure 7. Sensitivity maps for $(a-c)$ MHYDAS, (d-f) STREAM, (g-i) PESERA, and (j-1) MESALES in spatially homogeneous configurations. Precipitation and runoff conditions increase from left to right for each model, except for MESALES, which is mapped in a median runoff condition but for increasing precipitation. Soil loss isovalues are in $\mathrm{t} \mathrm{ha}^{-1}$ event ${ }^{-1}$ for MHYDAS and STREAM and in $\mathrm{t} \mathrm{ha}^{-1} \mathrm{yr}^{-1}$ for PESERA and MESALES. 


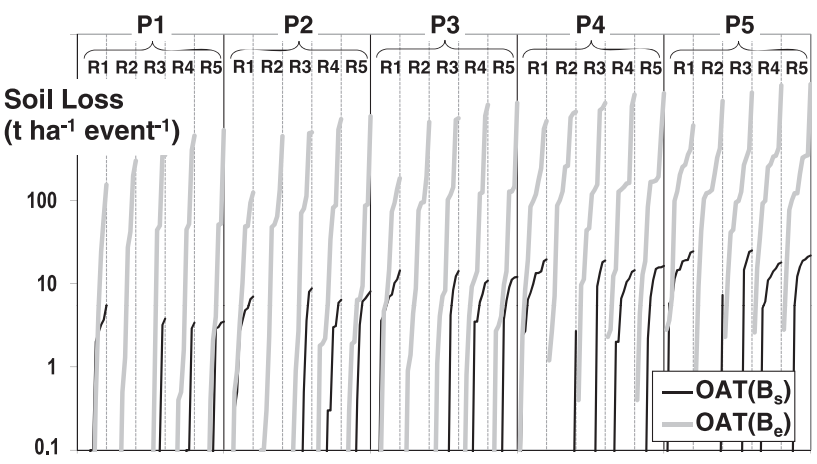

(a) MHYDAS - model results in distributed configurations

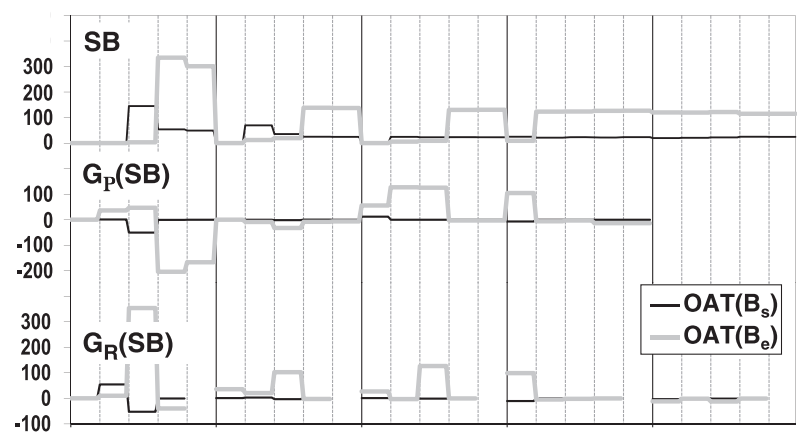

(c) MHYDAS - sensitivities to spatial distributions

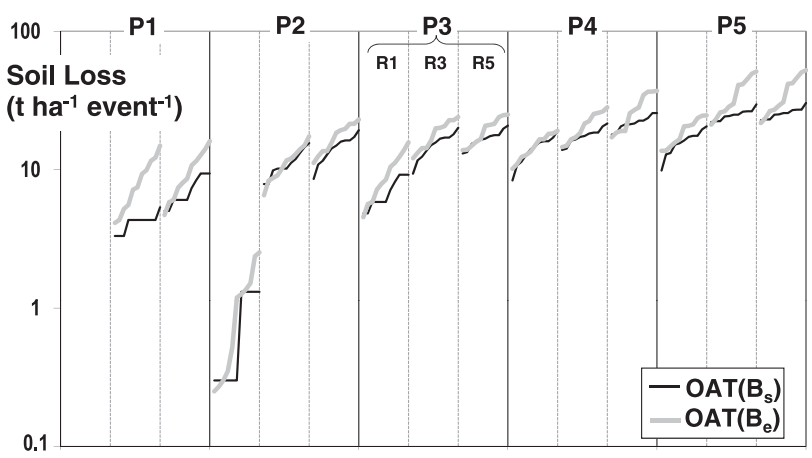

(b) STREAM - same key as (a)

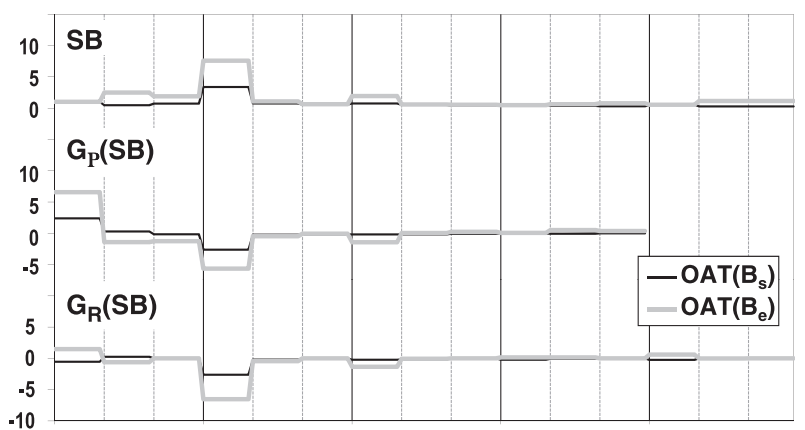

(d) STREAM - same key as (c)

Figure 8. Dashboards representing soil loss, dispersion SB, and variations in SB for (a, c) MHYDAS and $(b, d)$ STREAM under all combinations of precipitation $P$ and runoff conditions $R$ for OAT screenings (Figure 4b) involving spatial distributions of the equivalent slope $B_{s}$ or erodibility $B_{e}$.

into account by the model: soil loss values depend only on the cell values of the equivalent parameters, not on the connectivity between cells. For PESERA, a rule of thumb is that configurations involving the same number of "high" values in Figure 2, for all their patterns, yield approximately the same soil losses.

[42] The order of magnitude of soil loss results obtained in spatially distributed configurations (Figure 9a) is somewhat inferior to that obtained from spatially homogeneous settings (Figure 6a), whereas about the same difference exists in relative extension of results associated with $\operatorname{OAT}\left(B_{s}\right)$ and $\mathbf{O A T}\left(B_{e}\right)$, to the advantage of the latter. Figure $9 \mathrm{c}$ reports clear trends in terms of dispersion of the results. $\mathbf{S B}(\mathbf{s})$ has a constant value of 2 , and $\mathbf{S B}(\mathbf{e})$ decreases with increasing $R$ conditions, i.e., with reduced percentage of vegetal cover and increased crusting. Moreover, this decrease tends to be more remarkable for higher values of $P$. Values of $\mathbf{S B}(\mathbf{e})$ range between 20 and 40, which is nonnegligible before calculated soil losses.

\subsubsection{MESALES}

[43] MESALES shows very comparable features in terms of magnitude of soil loss results (Figure 9b) and sensitivity trends (Figure 9d) for spatially distributed or spatially homogeneous settings (Figures $6 \mathrm{~b}$ and $6 \mathrm{~d}$ ). The progression in numerical values is even smoother as a function of $P$ and $R$ conditions than it was in Figure 6b. With the same explanation as for PESERA, one observes discrete levels of values inside the dotted columns. Configurations $B 1$ and $B 3$ are the least efficient of the $B_{s}$ series, the most efficient ones being $B 6$ and $B 9$. With respect to $B_{e}$, the least efficient ones are $B 1$ and $B 7$, and the most efficient are $B 10$ and $B 5$. The values of $\mathbf{S B}(\mathbf{s})$ remain weak, but those of SB $(\mathbf{e})$ become nonnegligible under strong $P$ values and median $R$ values, which corresponded to changes in land use for moderately contributing land uses.

\subsubsection{Sensitivity Maps}

[44] Sensitivity maps obtained from tests involving spatially distributed configurations are shown in Figure 10 and are organized as in Figure 7. These maps were plotted from screenings described in Figure $4 \mathrm{~b}$ for STREAM and in Figure $4 \mathrm{c}$ for MHYDAS, PESERA, and MESALES. As $(P$, $R$ ) conditions strengthen, MHYDAS (Figures 10a-10c) evolves from a situation where equivalent erodibility dominates to a situation where combined spatially distributed effects gain more importance. A comparable behavior is suspected for STREAM (Figures 10d-10f) but could not be proven. For PESERA (Figures 10g-10i), soil loss values are stretched along the diagonal, indicating dominant combined effects for all the $(P, R)$ conditions considered. The results shown for MESALES (Figures $10 \mathrm{j}-10 \mathrm{l}$ ) were obtained for increasing $P$ conditions combined with a constant $R$ condition, corresponding to arable lands with median crusting. The maps are first dominated by equivalent slope effects (Figure 10j), then by both equivalent erodibility and equivalent slope (Figure 10k), with combined distributed values resulting in second-order effects (Figure 101), which requires further investigation or reveals the limitations of the graphical facilities chosen in Figure 4c. 


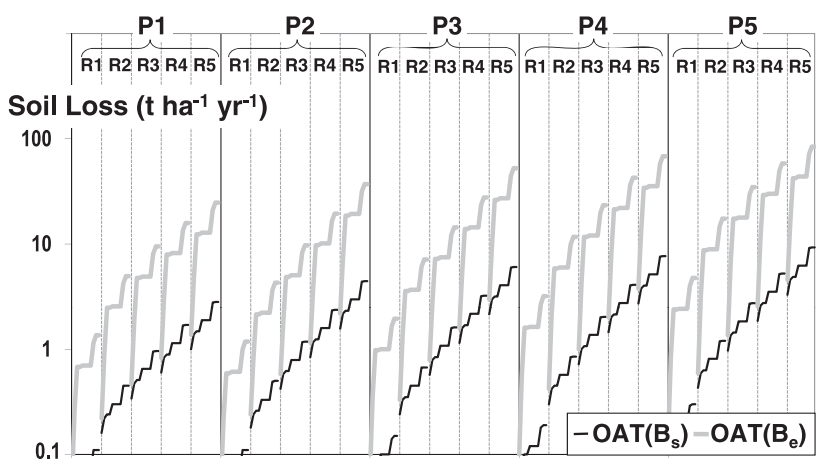

(a) PESERA - model results in distributed configurations

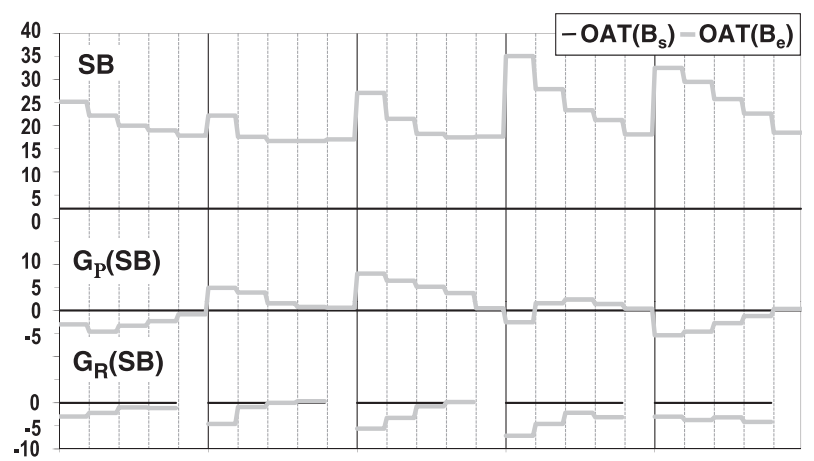

(c) PESERA - sensitivities to spatial distributions

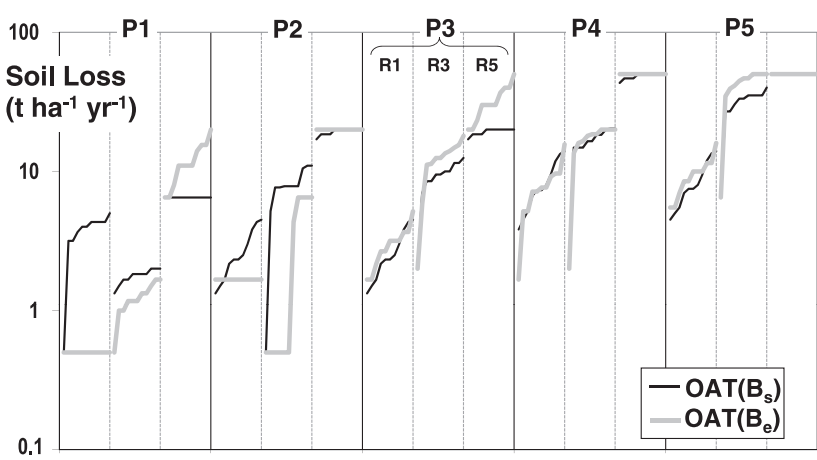

(b) MESALES - same key as (a)

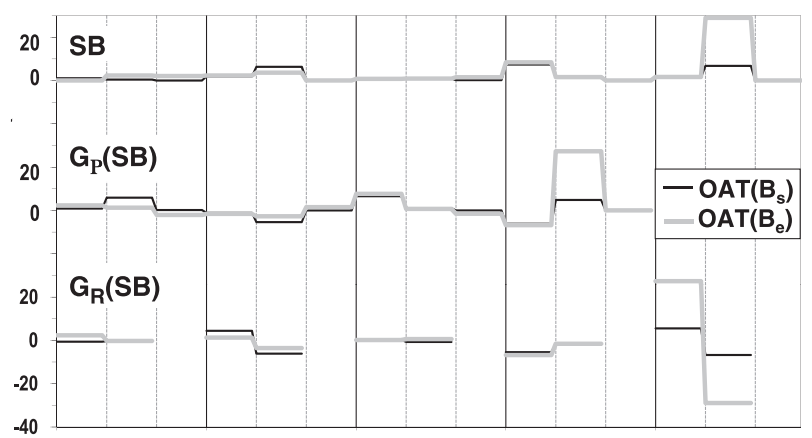

(d) MESALES - same key as (c)

Figure 9. Dashboards representing soil loss, dispersion $\mathrm{SB}$, and variations in $\mathrm{SB}$ for (a, c) PESERA and $(b, d)$ MESALES under all combinations of precipitation $P$ and runoff conditions $R$ for OAT screenings (Figure 4b) involving spatial distributions of the equivalent slope $B_{s}$ or erodibility $B_{e}$.

\subsection{Comparative Sensitivity Results}

\subsubsection{Dispersion for Spatially Homogeneous} Configurations

[45] Normalized dispersions associated with screenings described in Figure 4a have been calculated by means of equation (1) and are given in Table 1 for selected $(P, R)$ conditions. For clarity, a normalized dispersion of 1.0 in Table 1 indicates that the raw dispersion of values is equal to the reference soil loss value, which is, for example, the case for raw values ranging between 0.5 and 1.5 times the reference value. A normalized dispersion of 10.0 therefore indicates that response values largely exceed the reference value.

[46] Table 1 exhibits similarities between MHYDAS and PESERA, associated with strong dispersion indices, whereas STREAM and MESALES show results more confined near reference values. For all models but MESALES, $\mathbf{S A}(\mathbf{e})$ is higher than $\mathbf{S A}(\mathbf{s})$, and Table 1 adds numerical information to the observations already made that models are more sensitive to $p_{e}$ than to $p_{s} . \mathbf{S A}(\mathbf{s})$ is about one third of SA(e) for STREAM, one tenth for PESERA, and one thirtieth for MHYDAS. SA(s, e) values associated with LH tests are stronger for the continuous models (MHYDAS and PESERA) than for the discrete ones (STREAM and MESALES), which emphasizes the difference between multiplicative and additive (or disconnected) sensitivity trends attributable to differences in model structures. Missing values in Table 1 correspond to zero soil loss results for MHYDAS and to unperformed calculations for STREAM.
Occasional zero values found for MESALES simply indicate no dispersion: some soil loss results were constant during OAT tests for which no change in predicted erosion risk classes was observed.

\subsubsection{Dispersion for Spatially Distributed}

\section{Configurations}

[47] Table 2 shows relative dispersion ratios $\mathbf{S}_{\mathbf{B} / \mathbf{A}}=$ SB/SA formed from equations (1)-(3) and used to compare the spreads of soil loss results obtained from screenings depicted in Figures $4 \mathrm{~b}$ and $4 \mathrm{a}$. Values less than unity for STREAM and PESERA indicate poor sensitivities to the tested spatial distributions of $p_{s}$ and $p_{e}$. In contrast, MESALES shows relative dispersions ranging from 0.0 to 15.2 , mainly variable with the $R$ condition. Tests on spatial patterns of erodibility induce stronger variations than tests on spatial patterns of equivalent slopes, especially in the median $R$ condition: the typical Mediterranean "vineyards with median crusting" condition is associated with the very dynamic model response already noticed. For MHYDAS, $\mathbf{S}_{\mathbf{B} / \mathbf{A}}$ values are systematically greater than $\mathrm{SA}$ values, which signals a high "multiplicative" sensitivity to the spatial distributions of $p_{s}$ and $p_{e}$.

\subsubsection{Dispersion From Higher-Order Effects}

[48] Table 3 shows relative dispersion ratios $\mathbf{S}_{\mathbf{B}^{*} / \mathbf{B}}=$ $\mathbf{S B}^{*} / \mathbf{S B}$, formed from equations (3) and (4), and $\mathbf{S}_{\mathbf{B}^{*} / \mathbf{A}}=$ $\mathbf{S B}^{*} / \mathbf{S A}$, formed from equations (1), (2), and (4), to compare the spreads of soil loss results obtained from screenings depicted in Figures 4c, 4b, and 4a. For example, 


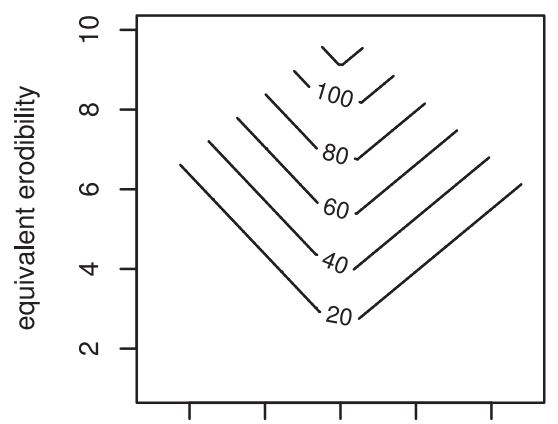

$\begin{array}{lllll}\text { a) } & 2 \quad 4 \quad 6 & 8 & 10\end{array}$

equivalent slope

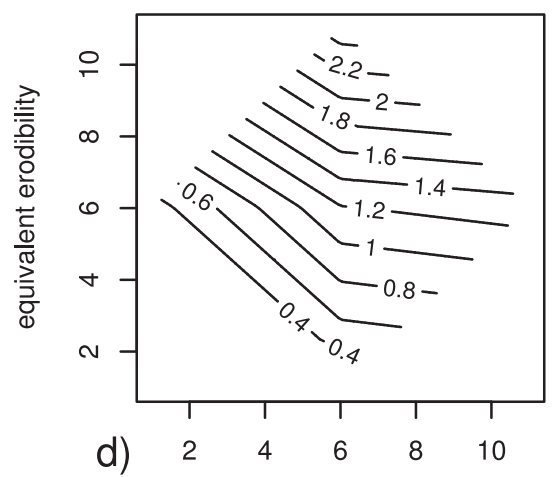

equivalent slope

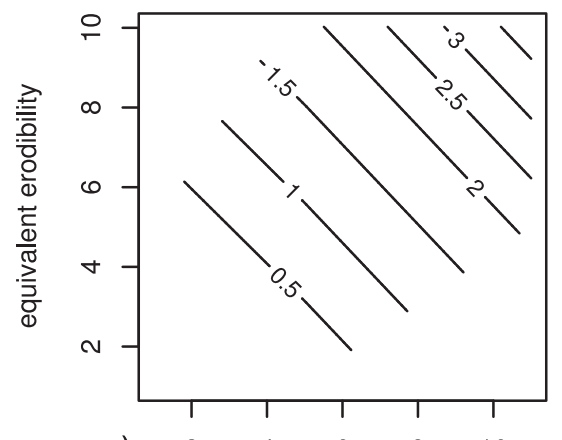

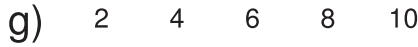

equivalent slope

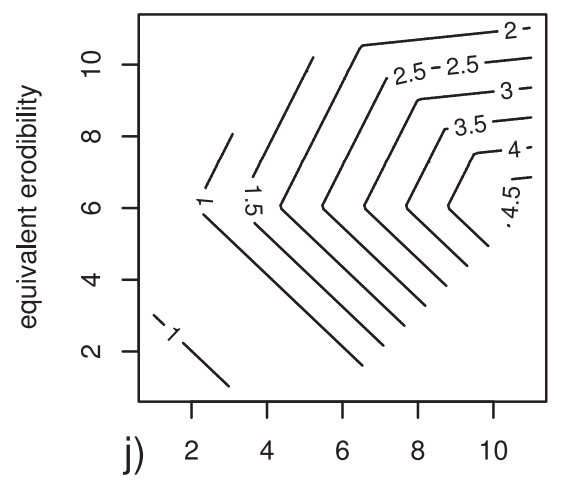

equivalent slope

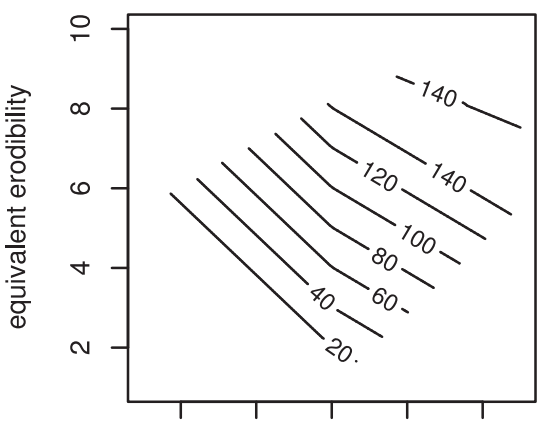

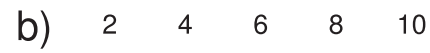

equivalent slope

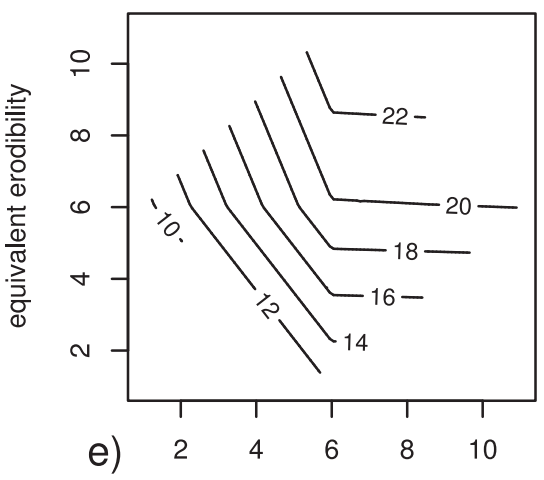

equivalent slope

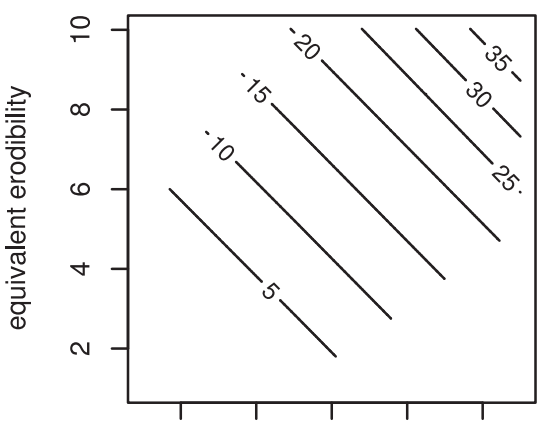

$\begin{array}{llllll}\text { h) } & 2 & 4 & 6 & 8 & 10\end{array}$

equivalent slope

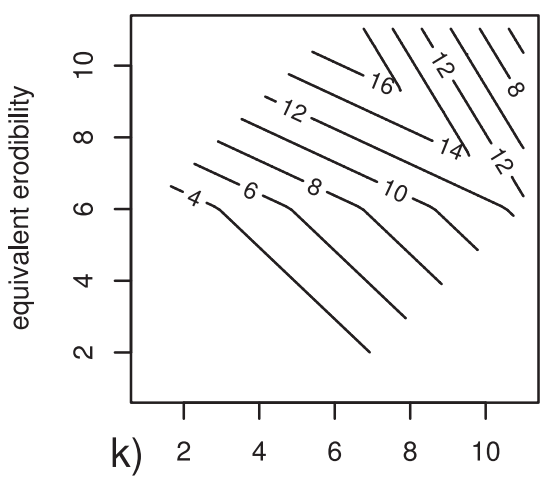

equivalent slope

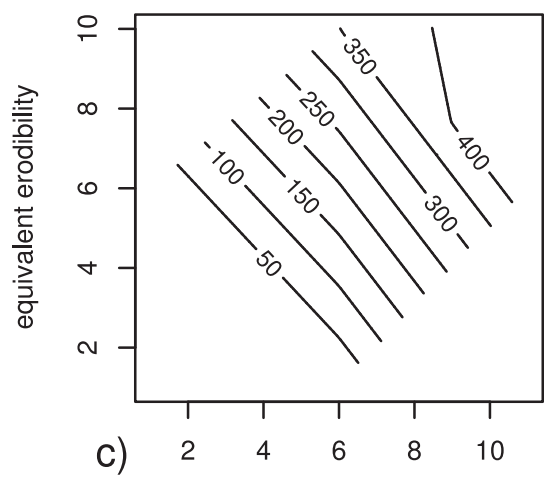

equivalent slope

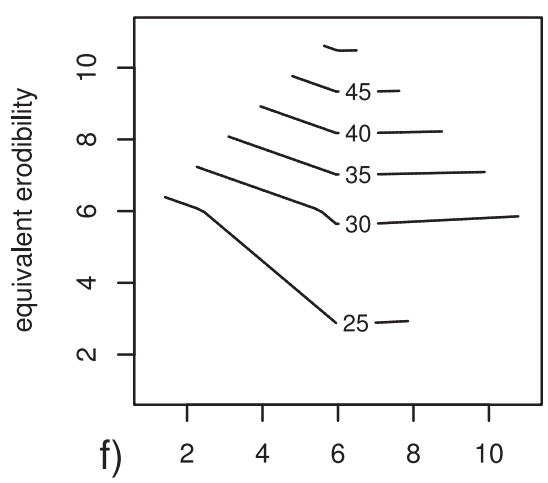

equivalent slope

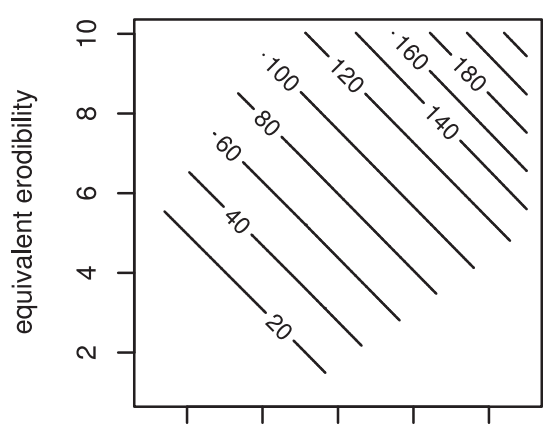

i) $\begin{array}{lllll}2 & 4 & 6 & 8 & 10\end{array}$

equivalent slope

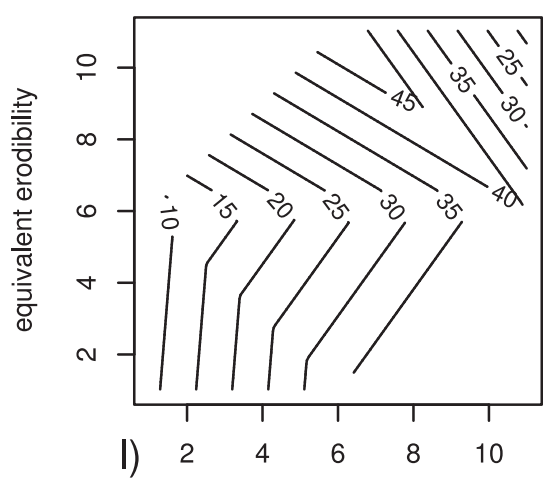

equivalent slope

Figure 10. Sensitivity maps for $(a-c)$ MHYDAS, $(d-f)$ STREAM, $(g-i)$ PESERA, and $(j-1)$ MESALES in spatially distributed configurations. Precipitation and runoff conditions increase from left to right for each model, except for MESALES, which is mapped in a median runoff condition but for increasing precipitation. Soil loss isovalues are in $\mathrm{t} \mathrm{ha}^{-1}$ event ${ }^{-1}$ for MHYDAS and STREAM and in $\mathrm{t} \mathrm{ha}^{-1} \mathrm{yr}^{-1}$ for PESERA and MESALES. 
Table 1. Selected SA Values Indicating Dispersion of Soil Loss Results Obtained from Screenings Shown in Figure 4a, Involving Spatially Homogeneous Configurations of Equivalent Slope $\left(p_{s}\right)$ and/or Equivalent Erodibility $\left(p_{e}\right)$, Tested One at a Time (OAT) or Together in Latin Hypercube (LH) Samples ${ }^{\mathrm{a}}$

\begin{tabular}{|c|c|c|c|c|c|c|c|c|c|c|c|}
\hline \multirow[b]{2}{*}{ Model } & \multirow[b]{2}{*}{ Screening } & \multirow[b]{2}{*}{ Dispersion } & \multicolumn{3}{|c|}{$P_{\min }$} & \multicolumn{3}{|c|}{$P_{\text {med }}$} & \multicolumn{3}{|c|}{$P_{\max }$} \\
\hline & & & $R_{\min }$ & $R_{\text {med }}$ & $R_{\max }$ & $R_{\min }$ & $R_{\text {med }}$ & $R_{\max }$ & $R_{\min }$ & $R_{\text {med }}$ & $R_{\max }$ \\
\hline \multirow[t]{3}{*}{ MHYDAS } & $\mathbf{O A T}\left(p_{s}\right)$ & $\mathbf{S A}(s)$ & - & - & 0.7 & - & 0.6 & 0.7 & 0.4 & 0.4 & 0.4 \\
\hline & $\mathbf{O A T}\left(p_{e}\right)$ & $\mathbf{S A}(e)$ & - & 9.1 & 13.9 & - & 5.4 & 12.0 & 8.7 & 10.6 & 11.5 \\
\hline & $\mathbf{L H}\left(p_{s}, p_{e}\right)$ & $\mathbf{S A}(s, e)$ & - & 36.9 & 85.0 & - & 6.4 & 54.1 & 47.5 & 47.7 & 46.0 \\
\hline \multirow[t]{3}{*}{ STREAM } & $\mathbf{O A T}\left(p_{s}\right)$ & $\mathbf{S A}(s)$ & $3.3^{\mathrm{b}}$ & 0.7 & 0.9 & 0.9 & 0.6 & 0.7 & 0.6 & 0.7 & 0.7 \\
\hline & $\operatorname{OAT}\left(p_{e}\right)$ & $\mathbf{S A}(e)$ & $9.3^{\mathrm{b}}$ & 4.4 & 3.4 & 3.5 & 1.8 & 1.7 & 1.7 & 2.6 & 2.6 \\
\hline & $\mathbf{L H}\left(p_{s}, p_{e}\right)$ & $\mathbf{S A}(s, e)$ & $13.3^{\mathrm{b}}$ & - & - & - & 2.3 & - & - & - & 3.7 \\
\hline \multirow[t]{3}{*}{ PESERA } & $\mathbf{O A T}\left(p_{s}\right)$ & $\mathbf{S A}(s)$ & 2.9 & 2.9 & 2.9 & 2.9 & 2.9 & 2.9 & 2.9 & 2.9 & 2.9 \\
\hline & $\mathbf{O A T}\left(p_{e}\right)$ & $\mathbf{S A}(e)$ & 37.7 & 30.0 & 26.7 & 40.6 & 27.3 & 26.4 & 48.7 & 38.6 & 27.7 \\
\hline & $\mathbf{L H}\left(p_{s}, p_{e}\right)$ & $\mathbf{S A}(s, e)$ & 113.3 & 90.0 & 80.3 & 121.9 & 82.0 & 79.3 & 146.3 & 115.9 & 83.2 \\
\hline \multirow[t]{3}{*}{ MESALES } & $\mathbf{O A T}\left(p_{s}\right)$ & $\mathbf{S A}(s)$ & 0.0 & 0.9 & 0.8 & 0.3 & 3.0 & 2.2 & 4.0 & 2.7 & 0.6 \\
\hline & $\operatorname{OAT}\left(p_{e}\right)$ & $\mathbf{S A}(e)$ & 0.0 & 0.7 & 2.1 & 0.0 & 2.1 & 1.5 & 0.0 & 1.9 & 0.0 \\
\hline & $\mathbf{L H}\left(p_{s}, p_{e}\right)$ & $\mathbf{S A}(s, e)$ & 0.7 & 3.0 & 2.7 & 4.3 & 9.9 & 2.3 & 10.3 & 7.5 & 0.6 \\
\hline
\end{tabular}

${ }^{\mathrm{a}}$ Dispersion was calculated as the spread of soil loss results obtained during OAT or LH simulations, normalized by the reference soil loss result of each model (equation (1)) for indicated precipitation $(P)$ and runoff $(R)$ conditions.

${ }^{\mathrm{b}}$ Values obtained for $P=2$ instead of $P=P_{\min }=1$.

differences in dispersions obtained from $\mathbf{O A T}\left(B_{s}^{*}\right)$ and OAT $\left(B_{s}\right)$ reveal the effect of spatial distributions of the "masked" parameter, here $B_{e}$.

[49] MHYDAS exhibits $\mathbf{S}_{\mathbf{B}^{*} / \mathbf{B}}(s)$ ratios from 2.7 to 30.6, tending to decrease with increasing $P$ and to increase with increasing $R$ conditions. These systematically high values indicate noticeable high-order effects, measuring a strong sensitivity to distribution of the "masked" equivalent erodibility. As MHYDAS is far less sensitive to distributions of the equivalent slope, $\mathbf{S}_{\mathbf{B}^{*} / \mathbf{B}}(e)$ ratios stay around unity. The exceptionally high $\mathbf{S}_{\mathbf{B}^{*} / \mathbf{B}}(e)$ ratio for $\left(P_{\min }, R_{\text {med }}\right)$ conditions is a numerical artifact associated with "divide by zero" problems.

[50] STREAM was not tested in $B^{*}$ configurations, so high-order effects could not be identified. Like STREAM, PESERA had weak $\mathbf{S}_{\mathbf{B} / \mathbf{A}}(s)$ and $\mathbf{S}_{\mathbf{B} / \mathbf{A}}(e)$ ratios, but then showed $\mathbf{S}_{\mathbf{B}^{*} / \mathbf{B}}(s)$ values between 13.4 and 24.6 and a stable $\mathbf{S}_{\mathbf{B}^{*} / \mathbf{B}}(e)$ value of about 1.5 , with the exception of an unexplained 2.1 value for $\left(P_{\mathrm{med}}, R_{\mathrm{max}}\right)$. The sensitivity of PESERA to spatial distributions of its superparameters is mostly due to high-order effects, with the dominating influence again being equivalent erodibility.

[51] For MHYDAS, PESERA, and MESALES, the $\mathbf{S}_{\mathbf{B}^{*} / \mathbf{A}}(s, e)$ ratio has very controlled values, not diverging with increased $(P, R)$ conditions associated with worst-case scenarios. High-order effects are largely responsible for sensitivity of the models to spatial distributions of their parameters. These effects are of comparable magnitudes in the spatially homogeneous and distributed cases.

\section{Conclusion}

[52] The introductory and theoretical work presented by Cheviron et al. [2010] was applied here for a comparative sensitivity analysis of four distributed erosion models: MHYDAS, STREAM, PESERA, and MESALES. Beyond differences in their underlying concepts and nominal scales, common causal links exist in their internal structures, which the $(P, R, p)$ procedure tried to exploit best. The innate parameterization of each model was decomposed into categories accounting for input fluxes (precipitation $P$ ), propensity for surface flows (runoff conditions $R$ ), and erosion processes $(p)$ governed by values of the equivalent slope $\left(p_{s}\right)$ and equivalent erodibility $\left(p_{e}\right)$. Soil loss predictions expressed as multilocal model responses $M\left(P, R, p_{s}, p_{e}\right)$ achieve the ultimate possible reduction in dimensionality of the problem by resorting only to the four compulsory components of erosion models. Graphical and numerical comparisons in responses and sensitivity trends between models were made possible by coding all arguments of the $M$ function into small dimensionless integers and running models on the same virtual catchment. For spatially homogeneous

Table 2. Selected $\mathbf{S}_{\mathbf{B} / \mathbf{A}}$ Ratios of Dispersion Values Obtained From Screenings Involving Spatially Distributed $\left(B_{s}, B_{e}\right)$ and Spatially Homogeneous $\left(p_{s}, p_{e}\right)$ Configurations of Equivalent Slope and Equivalent Erodibility, Shown in Figures $4 \mathrm{a}$ and $4 \mathrm{~b}$

\begin{tabular}{|c|c|c|c|c|c|c|c|c|c|c|c|c|}
\hline \multirow[b]{2}{*}{ Model } & \multicolumn{2}{|c|}{ Screening } & \multirow[b]{2}{*}{ Relative Dispersion } & \multicolumn{3}{|c|}{$P_{\min }$} & \multicolumn{3}{|c|}{$P_{\text {med }}$} & \multicolumn{3}{|c|}{$P_{\max }$} \\
\hline & $B$ & $A$ & & $R_{\min }$ & $R_{\text {med }}$ & $R_{\max }$ & $R_{\min }$ & $R_{\mathrm{med}}$ & $R_{\max }$ & $R_{\min }$ & $R_{\text {med }}$ & $R_{\max }$ \\
\hline \multirow[t]{2}{*}{ MHYDAS } & OAT $\left(B_{s}\right)$ & $\mathbf{O A T}\left(p_{s}\right)$ & $\mathbf{S}_{\mathbf{B} / \mathbf{A}}(s)$ & - & - & 2.3 & - & 3.7 & 1.7 & 10.8 & 4.8 & 3.0 \\
\hline & OAT $\left(B_{e}\right)$ & $\operatorname{OAT}\left(p_{e}\right)$ & $\mathbf{S}_{\mathbf{B} / \mathbf{A}}(e)$ & - & 1.1 & 23.3 & - & 4.4 & 12.5 & 18.4 & 13.8 & 11.6 \\
\hline \multirow[t]{2}{*}{ STREAM } & OAT $\left(B_{s}\right)$ & $\operatorname{OAT}\left(p_{s}\right)$ & $\mathbf{S}_{\mathbf{B} / \mathbf{A}}(s)$ & $0.2^{\mathrm{a}}$ & 0.7 & 0.8 & 0.8 & 0.8 & 0.5 & 0.9 & 0.4 & 0.4 \\
\hline & OAT $\left(B_{e}\right)$ & $\mathbf{O A T}\left(p_{e}\right)$ & $\mathbf{S}_{\mathbf{B} / \mathbf{A}}(e)$ & $0.2^{\mathrm{a}}$ & 0.6 & 0.5 & 0.6 & 0.3 & 0.3 & 0.3 & 0.4 & 0.4 \\
\hline \multirow[t]{2}{*}{ PESERA } & OAT $\left(B_{s}\right)$ & $\mathbf{O A T}\left(p_{s}\right)$ & $\mathbf{S}_{\mathbf{B} / \mathbf{A}}(s)$ & 0.7 & 0.7 & 0.7 & 0.7 & 0.7 & 0.7 & 0.7 & 0.7 & 0.7 \\
\hline & OAT $\left(B_{e}\right)$ & $\mathbf{O A T}\left(p_{e}\right)$ & $\mathbf{S}_{\mathbf{B} / \mathbf{A}}(e)$ & 0.7 & 0.7 & 0.7 & 0.7 & 0.7 & 0.7 & 0.7 & 0.7 & 0.7 \\
\hline \multirow[t]{2}{*}{ MESALES } & OAT $\left(B_{s}\right)$ & $\operatorname{OAT}\left(p_{s}\right)$ & $\mathbf{S}_{\mathbf{B}, A}(s)$ & - & 0.4 & 0.0 & 2.7 & 0.3 & 0.1 & - & 2.5 & 0.0 \\
\hline & $\operatorname{OAT}\left(B_{e}\right)$ & $\mathbf{O A T}\left(p_{e}\right)$ & $\mathbf{S}_{\mathbf{B} / \mathbf{A}}(e)$ & - & 3.3 & 1.0 & - & 0.4 & 1.0 & - & 15.2 & - \\
\hline
\end{tabular}

${ }^{\text {a } V a l u e s ~ o b t a i n e d ~ f o r ~} P=2$ instead of $P=P_{\min }=1$. 
Table 3. Selected $\mathbf{S}_{\mathbf{B}^{* / \mathbf{B}}}$ and $\mathbf{S}_{\mathbf{B}^{* / \mathbf{A}}}$ Ratios of Dispersion Values Obtained From Screenings Involving Spatially Distributed $\left(B_{s}, B_{e}, B_{s}^{*}, B_{e}^{*}\right)$ and Spatially Homogeneous $\left(p_{s}, p_{e}\right)$ Configurations of Equivalent Slope and Equivalent Erodibility, Shown in Figure 4

\begin{tabular}{|c|c|c|c|c|c|c|c|c|c|c|c|c|}
\hline \multirow[b]{2}{*}{ Model } & \multicolumn{2}{|c|}{ Screening } & \multirow[b]{2}{*}{ Relative Dispersion } & \multicolumn{3}{|c|}{$P_{\min }$} & \multicolumn{3}{|c|}{$P_{\text {med }}$} & \multicolumn{3}{|c|}{$P_{\max }$} \\
\hline & $B^{*}$ & $A$ or $B$ & & $R_{\min }$ & $R_{\text {med }}$ & $R_{\max }$ & $R_{\min }$ & $R_{\text {med }}$ & $R_{\max }$ & $R_{\min }$ & $R_{\text {med }}$ & $R_{\max }$ \\
\hline \multirow[t]{3}{*}{ MHYDAS } & $\operatorname{OAT}\left(B_{*}^{*}\right)$ & OAT $\left(B_{s}\right)$ & $\mathbf{S}_{\mathbf{B}^{*} / \mathbf{B}}(s)$ & - & 2.7 & 30.6 & - & 10.4 & 19.2 & 4.6 & 12.5 & 20.5 \\
\hline & OAT $\left(B^{*}\right)$ & OAT $\left(B_{e}\right)$ & $\mathbf{S}_{\mathbf{B}^{*} / \mathbf{B}}(e)$ & - & 512.3 & 1.0 & - & 6.5 & 1.0 & 0.9 & 1.0 & 1.1 \\
\hline & $\mathbf{L H}\left(B_{s}^{*}, B_{e}^{*}\right)$ & $\mathbf{L H}\left(p_{s}, p_{e}\right)$ & $\mathbf{S}_{\mathbf{B}^{*} / \mathbf{A}}(s, e)$ & - & 2.9 & 2.8 & - & 3.3 & 3.0 & 2.8 & 3.2 & 2.8 \\
\hline \multirow[t]{3}{*}{ PESERA } & OAT $\left(B^{*}\right)^{e}$ & OAT $\left(B_{s}\right)$ & $\mathbf{S}_{\mathbf{B}^{*} / \mathbf{B}}(s)$ & 19.0 & 15.2 & 13.6 & 20.5 & 13.8 & 13.4 & 24.6 & 19.5 & 14.1 \\
\hline & OAT $\left(B_{e}^{*}\right)$ & OAT $\left(B_{e}\right)$ & $\mathbf{S}_{\mathbf{B}^{*} / \mathbf{B}}(e)$ & 1.5 & 1.5 & 1.5 & 1.5 & 1.5 & 2.1 & 1.5 & 1.5 & 1.5 \\
\hline & $\mathbf{L H}\left(B_{s}^{*}, B_{\rho}^{*}\right)$ & $\mathbf{L H}\left(p_{s}, p_{e}\right)$ & $\mathbf{S}_{\mathbf{B}^{*} / \mathbf{A}}(s, e)$ & 0.9 & 0.9 & 0.9 & 0.9 & 0.9 & 0.9 & 0.9 & 0.9 & 0.9 \\
\hline MESALES & $\mathbf{L H}\left(B_{*}^{*}, B^{*}\right)$ & $\mathbf{L H}\left(p_{s}, p_{e}\right)$ & $\mathbf{S}_{\mathbf{B}^{*} / \mathbf{A}}(s, e)$ & 0.0 & 1.0 & 0.5 & 0.2 & 0.1 & 0.4 & 0.1 & 0.1 & 0.0 \\
\hline
\end{tabular}

patterns of erosion processes, sensitivity $G\left(P, R, p_{s}, p_{e}\right)$ was defined as a directional Gateaux derivative, yielding $G_{P}$, $G_{R}$, and $G_{p}$ values for variations involving $P, R$, or $p$, respectively. For spatially distributed patterns of erosion processes, sensitivity was measured as the normalized dispersion of soil loss results with respect to a reference median homogeneous case. The dependence of dispersion on hydrological $(P, R)$ conditions was studied, along with the ratio of dispersions obtained in the distributed and homogeneous cases.

[53] The estimated erosion rates ranged from 0 to $100 \mathrm{t}$ $\mathrm{ha}^{-1}$ event $^{-1}$ (MHYDAS and STREAM) or $\mathrm{t} \mathrm{ha}^{-1} \mathrm{yr}^{-1}$ (PESERA and MESALES) in most of the situations, but the continuous models (MHYDAS and PESERA) exhibited a more dynamic behavior than the discrete ones (STREAM and MESALES) through stronger variations in model outputs and sensitivity indices. This result goes against any a priori classification of sensitivity of the models by reference to their nominal scales and rather outlines the role played by innate structure or perhaps the calibration of the models in influencing their sensitivity scores.

[54] A major finding was that equivalent erodibility plays a dominant role over equivalent slope, except for MESALES, in which both entries have comparable weights. Sensitivity trends, nevertheless, fluctuate under varied hydrological $(P, R)$ conditions, which emphasizes the interest in and relevancy of performing a separation between what is due to hydrology and what is specific to topography or soil vulnerability in model predictions. All models showed comparable sensitivities to their hydrological conditions and equivalent erodibilities, whereas numerous model specificities appeared in detailed analysis. Soil loss results were of the same order of magnitude when testing spatially homogeneous or distributed configurations of equivalent slope and equivalent erodibility. Combined tests involving both parameters showed multiplicative, though not diverging, sensitivity effects for the continuous models, additive trends for STREAM, and disconnected sensitivities for MESALES. A probable consequence is the overestimation of actual erosion rates by MHYDAS and PESERA in worst-case scenarios.

[55] The $(P, R, p)$ procedure may unveil sensitivity trends hidden behind the complexity of the models whose physical basis involves nonexplicit interactions between parameters. For MHYDAS and STREAM, it was possible from sensitivity curves to localize the threshold in $(P, R)$ conditions between low water excess conditions, where diffuse erosion dominates, and high water excess conditions, in which linear erosion takes over. Intermediate $(P, R)$ conditions are expected regions of high sensitivity for small- scale models distinguishing diffuse and concentrated erosion processes, whereas no such tipping points are visible for coarser models.

[56] All four models showed behaviors consistent with current knowledge on soil erosion. They could therefore be used to model distributed erosion processes on hillslopes during rain events (MHYDAS and STREAM) or to predict seasonal erosion rates on larger territories (PESERA and MESALES), provided sufficiently reliable input parameter values are available. In particular, model results are expected to be strongly affected by uncertainties in erodibility arising from imprecise cartography or lack of information on soil characteristics.

\section{Notation}

$$
\begin{aligned}
A & \text { spatially homogeneous configurations. } \\
B & \text { spatially distributed configurations. } \\
B_{e}, B_{e}^{*} & \text { spatially distributed equivalent erodi- } \\
& \text { bilities. } \\
B_{s}, B_{S}^{*} & \text { spatially distributed equivalent slopes. } \\
e & \text { equivalent erodibility. } \\
G_{p}, G_{P}, G_{R} & \text { sensitivities to variations in } p, P, \\
& \text { and } R . \\
\mathbf{L H} & \text { variations in two or more parameters } \\
& \text { at once. } \\
M(X) & \text { model response at point } X \text { in para- } \\
& \text { meter space. } \\
\text { OAT } & \text { variations in a single parameter at a } \\
& \text { time. } \\
p & p_{e} \text { or } p_{s} . \\
P & \text { precipitation. } \\
p_{e}, p_{s} & \text { spatially homogeneous equivalent erodi- } \\
& \text { bility and equivalent slope. } \\
R & \text { runoff conditions. } \\
S & \text { equivalent slope. }
\end{aligned}
$$

SA, SB, SB* normalized dispersion of soil loss results in $A$ or $B$ configurations.

$\mathbf{S}_{\mathbf{B} / \mathbf{A}}, \mathbf{S}_{\mathbf{B}^{*} / \mathbf{A}}, \mathbf{S}_{\mathbf{B}^{*} / \mathbf{B}} \operatorname{ratios} \mathbf{S B} / \mathbf{S A}, \mathbf{S B}^{*} / \mathbf{S A}$, and $\mathbf{S B}^{*} / \mathbf{S B}$.

[57] Acknowledgments. This study is part of the ANR-MESOEROS21 project, granted by the French National Agency for Research. The authors wish to thank the peer reviewers, who helped improve the clarity and organization of the manuscript.

\section{References}

Boardman, J. (2006), Soil erosion science: Reflections on the limitations of current approaches, Catena, 68, 73-86. 
Brazier, R. E., K. J. Beven, J. Freer, and R. S. Rowan (2000), Equifinality and uncertainty in physically based soil erosion models: Application of the glue methodology to WEPP, the Water Erosion Prediction Project, for sites in the UK and USA, Earth Surf. Processes Landforms, 25, 825-845.

Cacuci, D. G. (1981), Sensitivity theory for non-linear systems. I. Nonlinear functional analysis approach, J. Math. Phys., 22, 2794-2802.

Cacuci, D. G. (2003), Sensitivity and Uncertainty Analysis, vol. 1, Theory, Chapman and Hall, Boca Raton, Fla.

Castaings, W. (2007), Analyse de sensibilité et estimation de paramètres pour la modélisation hydrologique: Potentiel et limitations des méthodes variationelles. Ph.D. dissertation, Univ. Joseph Fourier, Grenoble, France.

Castaings, W., D. Dartus, F.-X. Le Dimet, and G.-M. Saulnier (2007), Sensitivity analysis and parameter estimation for the distributed modeling of infiltration excess overland flow, Hydrol. Earth Syst. Sci. Discuss., 4, $363-405$

Cerdan, O., Y. Le Bissonnais, A. Couturier, and N. Saby (2002a), Modelling interrill erosion in small cultivated catchments, Hydrol. Processes, $16,3215-3226$

Cerdan, O., V. Souchere, V. Lecomte, A. Couturier, and Y. Le Bissonnais (2002b), Incorporating soil surface crusting processes in an expert-based runoff model: Sealing and transfer by runoff and erosion related to agricultural management, Catena, 46, 189-2005.

Cheviron, B., Y. Le Bissonnais, S. J. Gumiere, R. Moussa, and D. Raclot (2010), Sensitivity analysis of distributed erosion models: Framework, Water Resour. Res., 46, W08508, doi:10.1029/2009WR007950.

de Roo, A. P. J., R. J. E Offermans, and N. H. D. T. Cremers (1996), LISEM: A single-event physically based hydrological and soil erosion model for drainage basins. II: Sensitivity analysis, validation and application, Hydrol. Processes, 10, 1119-1126.

Doherty, J. (2004), PEST: Model-independent parameter estimation, user's manual, Watermark Numer. Comput., 336 pp., Brisbane, Australia.

Evrard, O., O. Cerdan, B. van Wesemael, M. Chauvet, Y. Le Bissonnais, D. Raclot, K. Vandaele, P. Andrieux, and C. Bielders (2009), Reliability of an expert-based runoff and erosion model: Application of STREAM to different environments, Catena, 78, 129-141.

Gâteaux, R. (1913), Sur les fonctionnelles continues et les fonctionnelles analytiques, C. R.Acad. Sci., 157, 325-327.

Gobin, A., R. J. A. Jones, M. Kirkby, P. Campling, C. Kosmas, G. Govers, and A. R. Gentile (2004), Pan-European assessment and monitoring of soil erosion by water, Environ. Sci. Policy, 7, 25-38.

Gumiere, S. J., Y. Le Bissonnais, and D. Raclot (2009), Soil resistance to interrill erosion: Model parameterization and sensitivity, Catena, 77, 274-284.

Gumiere, S. J., D. Raclot, B. Cheviron, G. Davy, X. Louchart, J. C. Fabre, R. Moussa, and Y. Le Bissonnais (2010), MHYDAS-Erosion: A distributed single-storm water erosion model for agricultural catchment, Hydrol. Processes, in press.

Jetten, V., A. P. J. de Roo, and J. Guerif (1998), Sensitivity of the model LISEM to variables related to agriculture, in Modelling Soil Erosion by Water, NATO ASI Ser., Ser. I, pp. 339-349, Springer-Verlag, New York.

Jetten, V., A. P. J. de Roo, and D. Favis-Mortlock (1999), Evaluation of field-scale and catchment-scale soil erosion models, Catena, 3, 521-541.
Jetten, V., G. Govers, and R. Hessel (2003), Erosion models: Quality of spatial predictions, Hydrol. Processes, 17, 887-900.

Jetten, V., J. Boiffin, and A. de Roo (2005), Defining monitoring strategies for runoff and erosion studies in agricultural catchments: A simulation approach, Eur. J. Soil Sci., 47(4), 579-592.

Kirkby, M. J., B. J. Irvine, R. J. A. Jones, G. Govers, and the PESERA team (2008), The PESERA coarse scale erosion model for Europe. I. Model rationale and implementation, Eur. J. Soil Sci., 59, 1293-1306.

Knapen, A., J. Poesen, G. Govers, G. Gyssels, and J. Nachtergaele (2007), Resistance of soils to concentrated flow erosion: A review, Earth Sci. Rev., 80, 75-109.

Le Bissonnais, Y., C. Montier, J. Jamagne, J. Daroussin, and D. King (2002), Mapping erosion risk for cultivated soil in France, Catena, 46, $207-220$.

Licciardello, F., G. Govers, O. Cerdan, M. Kirkby, A. Vacca, and F. J. P. M. Kwaad (2009), Evaluation of the PESERA model in two contrasting environments, Earth Surf. Processes Landforms, 34, 629-640.

Merritt, W. S., R. A. Letcher, and A. J. Jakeman (2003), A review of erosion and sediment transport models, Environ. Modell. Software, 18, $761-799$.

Moussa, R., and C. Bocquillon (1996a), Algorithms for solving the diffusive wave flood routing equation, Hydrol. Processes, 10, 105-124.

Moussa, R., and C. Bocquillon (1996b), Criteria for the choice of floodrouting methods in natural channels, J. Hydrol., 186, 1-30.

Moussa, R., M. Voltz, and P. Andrieux (2002), Effects of the spatial organization of agricultural management on the hydrological behaviour of a farmed catchment during flood events, Hydrol. Processes, 16, 393-412.

Nearing, M. A., L. Deer-Ascough, and J. M. Laflen (1990), Sensitivity analysis of the WEPP hillslope profile erosion model, Trans. ASAE, 33, $839-849$.

Nord, G., and M. Esteves (2005), PSEM_2D: A physically based model of erosion processes at the plot scale, Water Resour. Res., 41, W08407, doi:10.1029/2004WR003690.

Souchere, V., D. King, J. Daroussin, F. Papy, and A. Capillon (1998), Effects of tillage on runoff directions: Consequences on runoff contributing areas within agricultural catchments, J. Hydrol., 206, 256-267.

Veihe, A., and J. Quinton (2000), Sensitivity analysis of EUROSEM using Monte Carlo simulation: I. hydrological, soil and vegetation parameters, Hydrol. Processes, 14, 915-926.

O. Cerdan, BRGM-RNSC, 3 avenue Claude-Guillemin, BP 36009 , F-45060 Orléans CEDEX 2, France.

B. Cheviron, S. J. Gumiere, Y. Le Bissonnais, UMR LISAH, INRA-IRDSupAgro, 2 place Viala, F-34060 Montpellier, France, (bruno.cheviron@) gmail.com)

A. Couturier and F. Darboux, UR 272, Science du Sol, Centre de recherche d'Orléans, INRA, CS 40001, F-45075 Orléans CEDEX 2, France.

J. F. Desprats, BRGM-RNSC, 1039 rue Pinville, F-34000 Montpellier, France.

D. Raclot, UMR LISAH, INRA-IRD-SupAgro, 5 impasse Chehrazade, 1004 Tunis, Tunisia. 